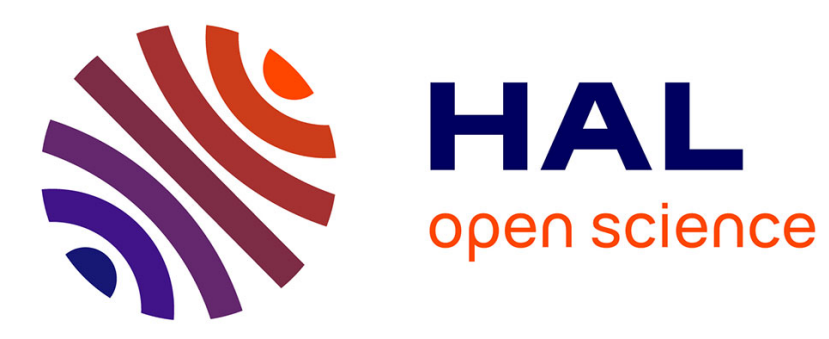

\title{
Modeling soil desiccation cracking by analytical and numerical approaches
}

\author{
Amade Pouya, Thi Dong Vo, Sahar Hemmati, Anh Minh A.M. Tang
}

\section{To cite this version:}

Amade Pouya, Thi Dong Vo, Sahar Hemmati, Anh Minh A.M. Tang. Modeling soil desiccation cracking by analytical and numerical approaches. International Journal for Numerical and Analytical Methods in Geomechanics, 2019, 43 (3), pp.738-763. 10.1002/nag.2887 hal-02130377

\section{HAL Id: hal-02130377 \\ https://hal-enpc.archives-ouvertes.fr/hal-02130377}

Submitted on 15 May 2019

HAL is a multi-disciplinary open access archive for the deposit and dissemination of scientific research documents, whether they are published or not. The documents may come from teaching and research institutions in France or abroad, or from public or private research centers.
L'archive ouverte pluridisciplinaire HAL, est destinée au dépôt et à la diffusion de documents scientifiques de niveau recherche, publiés ou non, émanant des établissements d'enseignement et de recherche français ou étrangers, des laboratoires publics ou privés. 
2 Amade Pouya ${ }^{1}$, Thi Dong Vo ${ }^{1,2}$, Sahar Hemmati ${ }^{2}$ and Anh Minh Tang ${ }^{1}$

$3 \quad{ }^{1}$ Université Paris Est, Laboratoire Navier (UMR8205), Marne-la-Vallée, France

$4{ }^{2}$ Université Paris Est, GERS/SRO, IFSTTAR, Marne-la-Vallée, France

8 Corresponding author:

9 Dr. Anh Minh TANG

10 Ecole des Ponts ParisTech

11 6-8 avenue Blaise Pascal, Cité Descartes, Champs sur Marne

1277455 Marne-la-Vallée, Cedex 2, France

13 Phone: +33164153563

14 Email: anhminh.tang@enpc.fr

15

16

17

18 
An energy approach is proposed as a complement to the stress approach commonly considered for investigating soil desiccation cracking. The elastic strain energies before and after crack initiation are estimated by both numerical and analytical solutions. The energy released by cracking is then compared to the fracture energy to discuss crack initiation conditions. This leads to combined energy

24 and stress conditions for crack initiation following Leguillon's theory. An approximate analytical solution is derived from a variational formulation of the porous elastic body equations. A cohesive zone model and Finite Element code are used to simulate crack propagation in an unsaturated porous body. This analysis shows that the energy criterion is reached before the stress criterion, and this can explain unstable crack propagation at the beginning. The approximate analytical solution allows predicting correctly the crack depth and opening in its initiation stage.

30

31 Keywords: desiccation cracks, crack initiation, crack propagation, energy criterion, cohesive zone model. 
Soil desiccation cracking is a common phenomenon in geotechnical engineering. The reduction of moisture content during desiccation causes soil shrinkage by the invasion of air into the soil pores. At the same time, matrix suction increases and leads to the development of tensile stress in restrained conditions (by a frictional boundary condition, suction gradient, concentrations of stress, heterogeneity of soil, etc.). This tensile stress can exceed the soil strength and create a desiccation crack network [14]. These cracks, created by tensile stresses, are different from localization shear bands that occur under other stress conditions. They have specific physical and geometrical properties and the theoretical and numerical approaches to determine their geometry is also different from the methods used for strain localization and shear band formation. The formation and propagation of desiccation cracks are hydro-mechanical processes that can affect the soil permeability and compressibility, as well as its mechanical strength. This could explain the effect of desiccation cracking on the instability of earth slopes [5-7].

The main methods for studying soil desiccation cracking are the following. The field and laboratory experiments $[2,8-14]$ are used to study the morphology, geometry and development of the desiccation cracks and the effect of some parameters (e.g. specimen dimensions, boundary conditions, soil properties, and drying condition) on theirs formation. The theoretical methods [3,15-20] aim to predict the desiccation cracks geometry (depth and spacing between cracks). The numerical approaches are introduced to simulate the formation and propagation of cracks during desiccation or to characterize material properties that cannot be easily measured in laboratory because inaccessible. Different numerical methods have been used for this purpose: Finite Element Method (FEM), Discrete Element Method (DEM), JFEM (Joint Finite Element Method), and mesh-free method [21-30]. They have shown that the initiation and evolution of a crack network are influenced by various factors [1], which can be divided into two main groups: (i) the internal factors (soil characteristics, structure heterogeneity and sample dimensions); (ii) and the external factors (soil/mold interface, humidification/desiccation cycle, desiccation conditions). Quantitative studies on desiccation cracking 
usually focus on crack density, volume change, crack geometry and spacing. Crack depth and spacing are key variables in the analysis of soil cracking. Various predictive models of soil cracking have been proposed, based on different approaches, to estimate these parameters.

Lachenbruch [15] developed an analytical approach to analyze the contraction cracks in basalt and permafrost by using Linear Elastic Fracture Mechanics (LEFM). The author introduced the fictitious stress notion and showed that: as a single crack propagated to a given depth, the stress field in the vicinity of the crack was perturbed; and that a distance away the stress asymptotically approached the initial value. An approach was proposed to predict the spacing between cracks from the theoretical stress relief field by assuming that the subsequent crack could propagate at approximately $5-10 \%$ of stress relief.

Konrad \& Ayad [19] applied the concept introduced by Lachenbruch [15] to predict the crack depth at the onset of the formation of the primary cracks, as well as the average crack spacing. They calculated first the stress intensity factor $K_{I}$ as a function of different crack depths. The depth of crack propagation at the time of initiation corresponded to that giving $K_{I}$ equal to the soil's fracture toughness $K_{I C}$. The crack propagation was analyzed with a trapezoidal distribution of horizontal tensile stress. The crack spacing was determined from the horizontal stress field in the neighborhood of an existing crack calculated by the FEM. The prediction of crack spacing was similar to the work of Lachenbruch [15], in which the subsequent crack initiated in the vicinity of an existing crack when the horizontal stress reached $95 \%$ of the soil tensile strength. The analysis made by Konrad \& Ayad [19] allowed predicting accurately the crack depth at the onset of the primary cracks by using the stress concept. However, the results depended on an arbitrary value of $95 \%$ of the tensile strength to initiate the subsequent crack. Moreover, this analysis did not give any information about the displacement fields of the soil and crack opening after crack initiation.

The LEFM, used to study the propagation of a single crack, was equally applied to predict the crack depth from the suction profile and soil properties $[2,16]$. However, the approaches developed in these works cannot be used to predict the crack spacing. 
Penev \& Kawamura [31] proposed a relationship to predict the crack spacing and the crack opening in a pavement layer composed of cement. The solution can be applied to a given thickness of material subjected to uniform shrinkage, and the crack depth was not considered. Chertkov [32,33] developed a physically based probabilistic model, using a multiple cracking and fragmentation model available for rocks, to predict the crack network geometry of swelling clayey soils. The model allowed estimating the crack opening, cross-sectional area and volume of cracks for a given water content profile and shrinkage curve of clay soil. However, two fundamental parameters of the model, the average spacing between cracks and the crack connectedness, were introduced in the model as a specific function of depth.

Moreover, using desiccation cracking test results and numerical simulation, Peron et al. [34] proposed a consistent explanation for the formation of desiccation crack patterns in soils. The authors gave an estimation of desiccation crack spacing by calculating the overall energy of the system. They assumed that the elastic strain energy was totally released during cracking and that all cracks penetrated to the full sample depth. This approach allowed estimating the number of blocks and thus the average crack spacing in a thin layer of soil, but it is not applicable for estimation of crack depth.

By using the LFEM, proposed by Lachenbruch [15] and developed by Konrad \& Ayad [19], the crack propagation condition $\left(K_{I}=K_{I C}\right)$ can be satisfied by two values of crack depth. The larger value corresponds to the ultimate depth of the crack that propagates unstably, while the smaller value represents the initial crack depth necessary for the onset of unstable propagation. Sanchez et al. [9] performed laboratory experiments to investigate soil desiccation cracking. The experimental data showed that the crack reached the ultimate depth in a very short time and that the subsequent evolution of crack depth was more gradual, corresponding to a stable propagation phase. The instable crack propagation depth needs then specific analysis which is different from the gradual and stable propagation. The present paper focuses on the initial instable propagation crack. The depth reached by the crack during this phase is named "ultimate depth" although it can be followed by a further increase during a stable propagation phase. The existing approaches described above are based on stress or energy criterion. However, theoretical approaches, initially proposed by Leguillon [33], have shown 
113 that a combined stress and energy criterion was needed to characterize crack initiation conditions at

114 the surface of a homogeneous material $[35,36]$. A combined energy and stress approach was recently

115 used [37] to analyze desiccation cracks spacing and depth. However, this work was based on very

116 sharp simplifications such as a constant suction profile in a horizontal thin layer of soil with constant

117 vertical stress and a shear stress linearly depending on the depth, etc.

118 In the present paper, a combined energy and stress approach is used as a complement to a moisture

119 diffusion problem in unsaturated soil in order to model the desiccation cracking. Unsaturated soil

120 models are usually extensions of saturated ones and this extension requires the definition of specific

121 state variables. Various expressions for the effective stress in unsaturated materials have been

122 proposed from early works of Roscoe et al. (1958) [38] and Bishop (1959) [39] to more recent works

123 based on energetic approaches [40]. A comprehensive review of effective stress formulations can be

124 found in [41]. Assuming the incompressibility of the solid matrix and the water phase, Houlsby (1997)

125 [42] established a general expression for the effective stress in unsaturated material that is used, with

126 some simplifications, in the present work. First, approximate solutions for the displacement fields of

127 the soil before and after crack initiation are proposed. The elastic strain energies for these two

128 moments are then calculated. The elastic energy released by cracking depends on both crack depth and

129 spacing. Its estimation allows predicting the crack depth corresponding to a given crack spacing. This

130 is supposed to be a first step towards a method predicting both the depth and spacing of desiccation

131 cracking based on a combination of energy and stress approaches. The proposed displacement field

132 allows calculating the crack opening and soil displacements after crack initiation. The approximate

133 analytical method is compared to the results of numerical simulations using FEM. This latter includes

134 a cohesive damage fracture law to model the moisture transfer, as well as the initiation and

135 propagation of a single crack. These investigations provide approximate analytical solution for

136 estimation of the crack depth due to soil desiccation in the initiation stage. 
Notation: In the sequel, light-face (Greek or Latin) letters denote scalars; underlined letters $(\underline{a})$ designate vectors and boldface letters (a) for second-order tensors; outline letters ( $£$ ) are used for 140 fourth-order tensors.

\section{Analytical approach}

In this analysis, the soil is represented as a homogeneous porous material subjected to potential cracking under desiccation. The study focuses on the initiation conditions and the geometry (e.g. depth, opening and spacing) of cracks by combining stress and energy approaches. The simultaneous apparition of cracks [34] is assumed to occur to create a crack network when the failure criterion is reached. The study focuses on the desiccation crack initiation near the top surface of the soil where the gravity-induced stresses are negligible. Thus, for the sake of simplicity, the gravity forces are neglected in the sequel and the governing equations of the problem read:

$$
\operatorname{div} \sigma=0, \quad \sigma^{\prime}=\mathrm{C}: \varepsilon
$$

149 where $\sigma$ represents the total stress, $\sigma$ ' the effective, $\boldsymbol{\varepsilon}$ the strain and $£$ corresponds to elastic tensor 150 (linear isotropic with Lamé coefficients $\lambda$ and $\mu$ ).

The definition of the effective stress is a key question in porous materials. In the linear poroelasticity, widely used to model fluid saturated porous materials, the following expression of the effective stress is used:

$$
\sigma^{\prime}=\sigma+b p \delta
$$

154 where $b$ is the Biot coefficient, $p$ is pore water pressure and $\delta$ the unit tensor. For unsaturated soils, assuming the incompressibility of the solid matrix and the water phase, Houlsby (1997) [42] established the following general expression for the effective stress:

$$
\boldsymbol{\sigma}^{\prime}=\boldsymbol{\sigma}-p_{a} \boldsymbol{\delta}+S\left(p_{a}-p_{w}\right) \boldsymbol{\delta}
$$



works showed that crack initiation took place when the saturation degree $S$ remained close to 1 $([10,11,45])$. As a result, and in order to be able to apply the theoretical methods of LEFM and linear poroelasticity in following analyses, $S$ is assumed to be equal to 1 for the effective stress calculation in this study. This does not exclude that the variation of $S$ is considered in the moisture diffusion problem. With this approximation, the same Eq. (2) can be formally used for the mathematical treatments of unsaturated soil by taking $p=-p_{w}$. In the sequel for simplicity and unity of notations the expression (2) is used in the theoretical relations but for the numerical models $b$ is taken equal to 1 . considered.

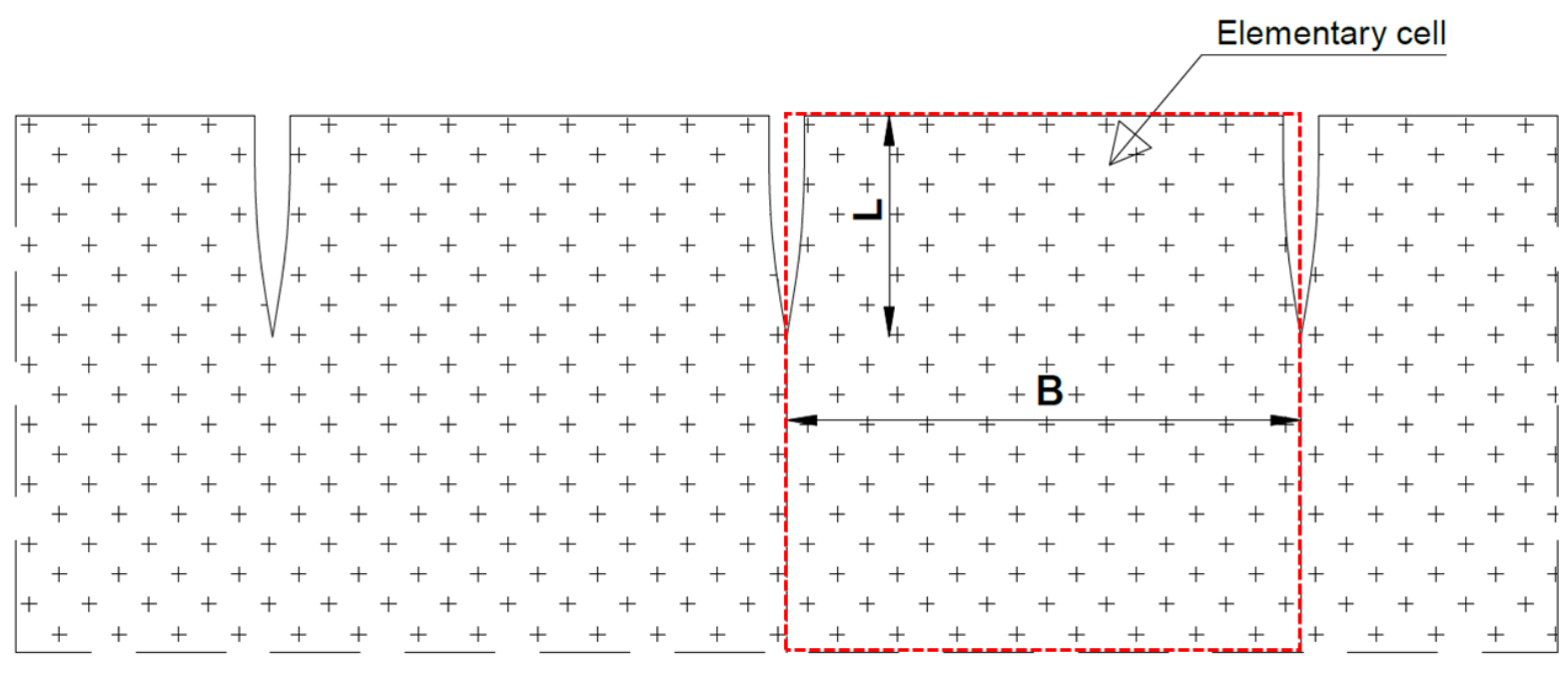

The energy approach consists of the calculation of the elastic strain energies before and after crack initiation with regular depth and spacing. The assumption of a regular set of cracks allows reducing the model to an elementary cell of spacing B (Figure 1). The symmetry of this problem allows reducing the model to a domain $\Omega$ containing two subdomains $\Omega^{1}$ and $\Omega^{2}$ with four boundaries $\partial_{x 0} \Omega ; \partial_{y 0} \Omega ; \partial_{L 1} \Omega ; \partial_{L 2} \Omega$ and a half spacing $D(D=B / 2)$ presented in Figure 2 (the $y$-axis is oriented downward). 


\subsection{Variational formulation of the problem} solution while respecting these assumptions.

The pore pressure field $p$ taking negative values corresponding to suction, results from the moisture transfer calculation in the numerical simulation. So, for mechanical calculation, it is supposed to be a known function of $y$ and: $\lim _{y \circledast ~} p(y)=0$. As the mechanism of desiccation cracking is related to tensile stress due to increase of suction during desiccation, variation of the pressure in the positive range has no effect on the desiccation cracking. The choice of this boundary condition simplifies the 
A variational formulation of the local equations governing the deformation of solids is very commonly used in order to build numerical approximate methods. The variational approach has been used extensively in linear elasticity but also for non-linear problems. In particular for the analysis of crack propagation it has been used in various works and a comprehensive review can be found in [46] . In this section, a variational formulation of the system of equations (I) is established in order to build approximate solutions. Then, Eq.(3) and the system (I) can be written under the effective stress form as follows:

$$
\begin{aligned}
& \forall \underline{x} \in \Omega ; \quad \operatorname{div} \sigma^{\prime}=b \nabla p \\
& \forall \underline{x} \in \partial_{x 0} \Omega \cup \partial_{L 2} \Omega ; \quad u_{x}(\underline{x})=0 \\
& \forall \underline{x} \in \partial_{L 1} \Omega ; \quad \sigma_{x x}^{\prime}(\underline{x})=b p(y) \\
& \forall \underline{x} \in \partial_{y 0} \Omega ; \quad \sigma_{y y}^{\prime}(\underline{x})=b p(0) \\
& \forall \underline{x} \in \partial_{x 0} \Omega \cup \partial_{y 0} \Omega \cup \partial_{L 1} \Omega ; \quad \sigma_{x y}^{\prime}(\underline{x})=0 \\
& \lim _{y \rightarrow \infty} \underline{u}(\underline{x})=0
\end{aligned}
$$

197 This local formulation is equivalent to the variational problem explained below. A set of kinematically admissible displacement fields $U_{A}$, satisfying the above displacement boundary conditions, is defined as: $U_{A} ; \underline{u} / \forall \underline{x} \in \partial_{x 0} \Omega \cup \partial_{L 2} \Omega ; u_{x}(\underline{x})=0$ and $\lim _{y \rightarrow \infty} \underline{u}(\underline{x})=0$

Thus, the solution of the system (II) is the displacement field that minimizes the following potential:

$$
\begin{aligned}
& \hookrightarrow=\frac{1}{2} \underset{\mathrm{W}}{\mathrm{\textrm {O }}} \boldsymbol{\varepsilon}: £: \boldsymbol{\varepsilon} d w-\underset{\mathrm{W}}{\mathrm{O}} \underline{f} \cdot \underline{u} d w-\underset{\mathbb{\Theta}_{T} \mathrm{~W}}{\grave{\mathrm{O}}} \underline{T} \cdot \underline{u} d s \\
& \text { Where: }\left\{\begin{array}{l}
\underline{x} \in \Omega ; \quad \underline{f}=-b \nabla p \quad(\underline{f} \text { is volumetric force }) \\
\partial_{T} \Omega=\partial_{L 1} \Omega \cup \partial_{y 0} \Omega \\
\underline{x} \in \partial_{L 1} \Omega ; \underline{T}=b p(y) \underline{n}(\underline{x})=b p(y) \underline{e}_{x} \\
\underline{x} \in \partial_{y 0} \Omega ; \underline{T}=b p(0) \underline{n}(\underline{x})=-b p(0) \underline{e}_{y}
\end{array}\right.
\end{aligned}
$$

201 By assuming that $\boldsymbol{\varepsilon}^{s}$ and $\underline{u}^{s}$ are the strain and displacement solutions of the system (II) for $L \neq 0$, the following inequality can be written for every admissible displacement $\underline{u} \in U_{A}$ : 


$$
\hookrightarrow(\underline{u}) \geq \hookrightarrow\left(\underline{u^{S}}\right)
$$

Moreover, it can be established that, for the solutions $\underline{u}^{s}$ and $\varepsilon^{s}$ [47]:

$$
\underset{\mathrm{W}}{\mathrm{\textrm {O }}} \boldsymbol{\varepsilon}^{s}: £: \boldsymbol{\varepsilon}^{s} d w=\underset{\mathrm{W}}{\mathrm{O}} \underline{f} \cdot \underline{u}^{s} d w+\underset{\boldsymbol{\Phi}_{T} \mathrm{~W}}{\mathrm{O}} \underline{T} \cdot \underline{u}^{s} d s
$$

204 From Eq.(4) and Eq.(7), the potential $\hookrightarrow\left(\underline{u^{s}}\right)$ of the solutions can be deduced as follows:

$$
\hookrightarrow\left(\underline{u^{s}}\right)=-\frac{1}{2} \underset{\mathrm{W}}{\mathrm{O}} \boldsymbol{\varepsilon}^{s}: £: \boldsymbol{\varepsilon}^{s} d w
$$

205 The elastic strain energy of the porous elastic material can be deduced from the following analysis. If $206 \sigma$ designates the total stress, then a strain increment, produced by the external work $d W$, satisfies: $d W$ $207=\sigma: d \boldsymbol{\varepsilon}$. The porous-elastic constitutive law Eq.(2) can be written as:

$$
\sigma=\mathrm{C}:\left(\varepsilon-\varepsilon^{L}\right)
$$

208 where $\boldsymbol{\varepsilon}^{L}=\mathrm{C}^{-1}:$ bp $\boldsymbol{\delta}$. Then the external work increment becomes:

$$
d W=\boldsymbol{\sigma}: d \boldsymbol{\varepsilon}=\left(\boldsymbol{\varepsilon}-\boldsymbol{\varepsilon}^{L}\right): \mathrm{C}: d \boldsymbol{\varepsilon}
$$

In the present work, the pore pressure field is determined by a moisture transfer calculation, and the effect of deformation on pore pressure is not considered. In addition, the crack propagation at the initiation phase is very quick. Thus, the pore pressure fields before and after crack initiation are supposed to be similar. Therefore, $\varepsilon^{L}$ remains constant in the crack initiation phase. Eq. (10) is integrated in:

$$
d W=d\left[\frac{1}{2}\left(\boldsymbol{\varepsilon}-\boldsymbol{\varepsilon}^{L}\right): \mathrm{C}:\left(\boldsymbol{\varepsilon}-\boldsymbol{\varepsilon}^{L}\right)\right]
$$

214 The elastic strain energy released by the cracking process is then given by:

$$
\Delta E=\frac{1}{2} \Delta \int_{\Omega}\left(\boldsymbol{\varepsilon}-\boldsymbol{\varepsilon}^{L}\right): \mathrm{C}:\left(\boldsymbol{\varepsilon}-\boldsymbol{\varepsilon}^{L}\right) d \Omega
$$


215 The elastic strain energy before cracking, $E^{\text {before }}$, is analytically calculated from the displacements 216 field, which is the solutions of the system (II) with $L=0$. The elastic strain energy after crack 217 initiation $E^{a f t e r}$ is deduced from the displacement solution of the system (II) with $L \neq 0$. The variational 218 formulation allows establishing an upper estimation of the elastic strain energy after crack initiation:

$E^{\text {after }}=\frac{1}{2} \int_{\Omega}\left(\boldsymbol{\varepsilon}^{s}-\boldsymbol{\varepsilon}^{L}\right): \mathrm{C}:\left(\boldsymbol{\varepsilon}^{s}-\boldsymbol{\varepsilon}^{L}\right) d \Omega=\frac{1}{2} \int_{\Omega} \boldsymbol{\varepsilon}^{s}: \mathrm{C}: \boldsymbol{\varepsilon}^{s} d \Omega-\int_{\Omega} \boldsymbol{\varepsilon}^{s}: \mathrm{C}: \boldsymbol{\varepsilon}^{L} d \Omega+\frac{1}{2} \int_{\Omega} \boldsymbol{\varepsilon}^{L}: \mathrm{C}: \boldsymbol{\varepsilon}^{L} d \Omega$

219 The second integral of this equation can be transformed as follows:

$$
\grave{\mathrm{O}}_{\mathrm{W}} \varepsilon^{L}: £: \varepsilon^{s} d \mathrm{~W}=\grave{\mathrm{O}}_{\mathrm{W}} b p \boldsymbol{\delta}: \varepsilon^{s} d \mathrm{~W}=\grave{\mathrm{O}}_{\mathrm{W}} b p \|_{i} u_{i}^{s} d \mathrm{~W}
$$

This Eq.(14) can be integrated by parts, yielding:

$$
\grave{\mathrm{O}}_{\mathrm{W}} b p \rrbracket_{i} u_{i}^{s} d \mathrm{~W}=\grave{\mathrm{O}}_{q \mathrm{~W}} b p u_{i}^{s} n_{i} d \mathrm{~W}-\grave{\mathrm{O}}_{\mathrm{W}} b u_{i}^{s} \rrbracket_{i} p d \mathrm{~W}
$$

Integration of $\partial \Omega$ can be decomposed into integration of $\partial_{u} \Omega$ (on which the displacement is prescribed) and $\partial_{f} \Omega$ (on which the surface traction is applied). Zero displacement is imposed on the boundaries $\left(\partial_{x 0} \Omega\right.$ and $\left.\partial_{L 2} \Omega\right)$. For these boundaries, the contribution of the first integral in Eq.(15) vanishes because $u_{i}^{s}=0$. The contribution to $\partial_{f} \Omega$ corresponds to the prescribed forces $\underline{T}$. In addition, by replacing the term $b \|_{i} p$ by $-f_{i}$ (see Eq.(5)), the integral of Eq.(15) can be transformed as follows:

$$
\grave{\mathrm{O}}_{\mathrm{W}} b p \|_{i} u_{i}^{s} d \mathrm{~W}=\grave{\mathrm{O}}_{\pi_{f} \mathrm{~W}} T_{i} u_{i}^{s} d \mathrm{~W}+\grave{\mathrm{O}}_{\mathrm{W}} f_{i} u_{i}^{s} d \mathrm{~W}
$$

226 From the equations (7), (14) and (16), it can be deduced that:

$$
\grave{\mathrm{O}}_{\mathrm{W}} \boldsymbol{\varepsilon}^{L}: £: \varepsilon^{s} d \mathrm{~W}=\grave{\mathrm{O}}_{\mathrm{W}} \boldsymbol{\varepsilon}^{s}: £: \boldsymbol{\varepsilon}^{s} d \mathrm{~W}
$$

227 By replacing Eq. (17) in Eq. (13), the following is obtained:

$$
E^{a f t e r}=-\frac{1}{2} \grave{\mathrm{O}}_{\mathrm{W}} \boldsymbol{\varepsilon}^{s}: £: \boldsymbol{\varepsilon}^{s} d \mathrm{~W}+\frac{1}{2} \grave{\mathrm{O}}_{\mathrm{W}} \boldsymbol{\varepsilon}^{L}: £: \varepsilon^{L} d \mathrm{~W}
$$

228 The same analysis can be done for the displacements and strains fields before cracking, denoted by $\underline{u}^{0}$ and $\boldsymbol{\varepsilon}^{0}$, and it can be found that:

$$
E^{\text {before }}=-\frac{1}{2} \grave{\mathrm{O}}_{\mathrm{W}} \varepsilon^{0}: £: \varepsilon^{0} d \mathrm{~W}+\frac{1}{2} \grave{\mathrm{O}}_{\mathrm{W}} \varepsilon^{L}: £: \varepsilon^{L} d \mathrm{~W}
$$


230 The difference between elastic strain energies before and after crack initiation using the Eqs.(18), (19),

231 and (8) can be calculated as:

$$
E^{\text {before }}-E^{a f t e r}=-\frac{1}{2} \grave{\mathrm{O}}_{\mathrm{W}} \boldsymbol{\varepsilon}^{0}: £: \varepsilon^{0} d \mathrm{~W}+\frac{1}{2} \grave{\mathrm{O}}_{\mathrm{W}} \boldsymbol{\varepsilon}^{s}: £: \varepsilon^{s} d \mathrm{~W}=-\frac{1}{2} \grave{\mathrm{O}}_{\mathrm{w}} \boldsymbol{\varepsilon}^{0}: £: \varepsilon^{0} d \mathrm{~W}-\hookrightarrow\left(\underline{u}^{s}\right)
$$

232 Using Eq.(6) for an approximate solution $\underline{u}$, from Eq.(20), yields:

$$
E^{\text {before }}-E^{\text {after } 3}-\frac{1}{2} \grave{\mathrm{O}}_{\mathrm{W}} \boldsymbol{\varepsilon}^{0}: £: \boldsymbol{\varepsilon}^{0} d \mathrm{~W}-\quad \hookrightarrow(\underline{u})
$$

233 The energy-based method for analyzing crack propagation consists of calculating the energy released

234 by cracking and comparing it with the surface energy needed to create a crack. If the fracture energy 235 dissipation rate is designated by $G^{c}$, with $G^{c}=2 \gamma^{s}$ where $\gamma^{s}$ is specific rupture energy per unit surface 236 (depth in 2D geometry), then the energy condition for crack propagation is expressed by:

$$
E^{\text {before }}-E^{\text {after } 3} G^{c} L
$$

237 Thus, by using Eq.(21), a sufficient condition to satisfy the energy condition in (22) is:

$$
-\quad \hookrightarrow(\underline{u})-\frac{1}{2} \grave{\mathrm{O}}_{\mathrm{W}} \boldsymbol{\varepsilon}^{0}: £: \varepsilon^{0} d \mathrm{~W}^{3} \quad G^{c} L
$$

238 A simple analysis shows that, for small perturbations close to the initial state, the left side of Eq.(23) is 239 positive. By designating:

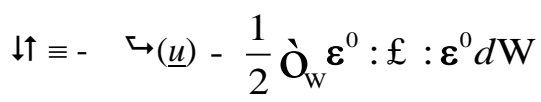

240 The energy criterion for crack propagation in Eq.(23) becomes:

$$
\downarrow \uparrow / L \geq G^{c}
$$

241 In the sequel, after calculating the energy before cracking, approximate solutions $\underline{u}$ for the state after 242 crack initiation are fitted to $\underline{u}^{s}$ to obtain close estimations of crack propagation conditions. 
245 The displacement solution before cracking corresponds to $L=0$ in the system (II), and the condition $u_{x}$

$246=0$ for every point with $x=0$ or $x=D$. The displacement solution is designated by $\underline{u}^{0}$ as follows:

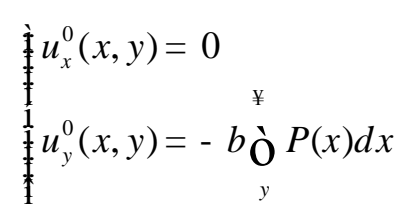

247 where $P=\frac{p(y)}{\lambda+2 \mu}$ is dimensionless. The elastic strain energy before cracking can be calculated from 248 Eq.(19):

$$
\frac{E^{\text {before }}}{\lambda+2 \mu}=b^{2} D \frac{1-\psi}{1+2 \psi} \int_{0}^{\infty} P^{2} d y
$$

249 With $\psi=\frac{\lambda}{\lambda+2 \mu}$. The term $\frac{1}{2} \grave{\mathrm{O}}_{\mathrm{w}} \boldsymbol{\varepsilon}^{0}: £: \varepsilon^{0} d \mathrm{~W}$ in Eq.(24) can also be calculated as:

$$
\frac{1}{2} \frac{\int_{\Omega} \varepsilon^{0}: \mathrm{C}: \varepsilon^{0} d \Omega}{\lambda+2 \mu}=\frac{1}{2} b^{2} D \int_{0}^{\infty} P^{2} d y
$$

b) After cracking

251 Exact analytical solution doesn't exist for the stress and displacement fields of problem (II) with $L \neq 0$.

252 An approximate solution of the displacement field can be proposed by minimizing the potential $\hookrightarrow(\underline{u})$

253 (Eq.(4)). This minimization is not applied in the space of all continuous functions in the domain $\Omega$ but 254 only in a subdomain of polynomial functions of $x$ and parameters $a_{n}(y)$ that depend on depth. Every 255 function $f(x, y)$ on the domain $\Omega=[0, D] \times[0, \infty[$ can be decomposed as:

$$
f(x, y)=\stackrel{̊}{̊}=0_{n}^{*} a_{n}(y) \frac{(x / D)^{n}}{n !}
$$


An approximate solution is considered by considering only the first terms up to the second degree of $x$ as follows:

$$
\begin{aligned}
& \frac{1}{1} u_{x}(x, y)=a_{0}(y)+a_{1}(y)(x / D)+a_{2}(y)(x / D)^{2} / 2 \\
& \frac{1}{1} u_{y}(x, y)=b_{0}(y)+b_{1}(y)(x / D)+b_{2}(y)(x / D)^{2} / 2
\end{aligned}
$$

258

The analysis of the symmetries of the problem (Figure 1) shows that $u_{x}$ must be an odd function of $x$, whereas $u_{y}$ must be a pair function. This leads to $a_{0}(y)=a_{2}(y)=b_{1}(y)=0$. The displacement field can be written as:

$$
\begin{aligned}
& u_{x}(x, y)=a_{1}(y) x / D \\
& u_{y}(x, y)=b_{0}(y)+b_{2}(y)(x / D)^{2} / 2
\end{aligned}
$$

The functions $a_{1}, b_{0}$ and $b_{2}$ are determined separately for $y \in[0, L]$ and $y \in[L, \infty]$, supposing the continuity of displacement in the entire domain and on the line $y=L$. Thus, two subdomains are considered and denoted by $\Omega^{1}=[0, D] \times[0, L] ; \Omega^{2}=[0, D] \times[L, \infty[$ (see Figure 2$)$.

In $\Omega^{1}$, the displacement fields, which satisfy the boundary conditions (II.2) and (II.6), are determined to find the elements of $U_{A}$ defined in the previous section. The momentum balance equation (II.1) and the force boundary conditions (II.4) should be satisfied in addition to the displacement boundary conditions. Therefore, the solution globally satisfies the equations (II.1), (II.2), (II.4) and (II.5). Additionally, the continuity of the displacement on the $\partial_{12} \Omega$ interface line $(y=L)$ imposes $u_{x}(D, L)=0$. This leads to the following expressions for $u_{x}$ and $u_{y}$ in $\Omega^{1}$ depending on only two constants, $C_{1}$ and $C_{2}$ :

$$
\underline{x} \in \Omega^{1} ;\left\{\begin{array}{l}
u_{x}(x, y)=\frac{C_{1}}{D}(y-L) x \\
u_{y}(x, y)=u_{y}^{0}(x, y)+C_{2}+\frac{\psi C_{1}}{D}\left(L y-\frac{y^{2}}{2}\right)-\frac{C_{1}}{2 D} x^{2}
\end{array}\right.
$$

271 In $\Omega^{2}$, the continuity of the displacement on the $\partial_{12} \Omega$ interface must be satisfied, in addition to the 272 displacement boundary conditions. It should be noted that $u_{y}^{0}(x, y)$ (the solution before cracking) satisfies the boundary conditions corresponding to $\Omega^{2}$ but not the continuity of displacement for the 
274 solution after cracking in the $\partial_{12} \Omega$ interface. The correction term $\mathrm{D} u$ is defined to satisfy this

275 condition without changing other boundary conditions. The solution is proposed with:

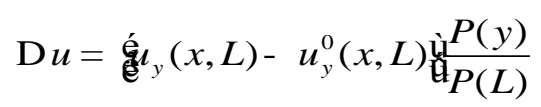

276 Because $\lim _{y \circledast m} P(y)=0$, the condition (II.6) will be satisfied by this assumption. The general 277 displacement expression will be given in $\Omega^{2}$ by:

$$
\underline{x} \in \Omega^{2} ;\left\{\begin{array}{l}
u_{x}(x, y)=0 \\
u_{y}(x, y)=u_{y}^{0}(x, y)+\left(C_{2}+\frac{\psi C_{1} L^{2}}{2 D}-\frac{C_{1}}{2 D} x^{2}\right) \frac{P(y)}{P(L)}
\end{array}\right.
$$

278 The approximate displacement field given by Eqs. (32) and (34) satisfies all the conditions apart from 279 the boundary conditions (II.3) for the $\Omega^{1}$ part and the momentum balance equation (II.1) for the $\Omega^{2}$ 280 part. In the sequel, the two constants $C_{1}$ and $C_{2}$ are determined by minimizing the potential $\hookrightarrow(\underline{u})$ to obtain the best approximation. Note that if $C_{1}=C_{2}=0$ in Eqs. (32) and (34), then the expression of the displacement field before cracking can be obtained.

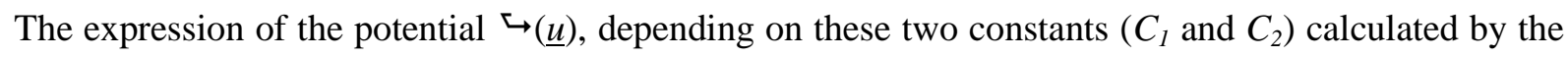
sum of the potential shown in Eq.(4) for the two subdomains $\Omega^{1}$ and $\Omega^{2}$, is given as follows:

$\hookrightarrow(\underline{u})$

$=(\lambda+2 \mu)\left[-\frac{1}{2} b^{2} D \int_{0}^{\infty} P^{2} d y+C_{1} b(\psi-1) P_{1}+\frac{\left(1-\psi^{2}\right) C_{1}^{2} L^{3}}{6 D}+\frac{(1-\psi) D C_{1}^{2}}{12 P_{L}^{2}} P_{2}+\frac{1}{2 P_{L}^{2}}\left(\frac{1}{D} \chi^{2}+\frac{C_{1}^{2} D^{3}}{20}-\chi \frac{C_{1} D}{3}\right) P_{3}\right]$

285 where $\chi=\left(\frac{2 D C_{2}+\psi C_{1} L^{2}}{2}\right)$ and the following constants depend on the pressure field:

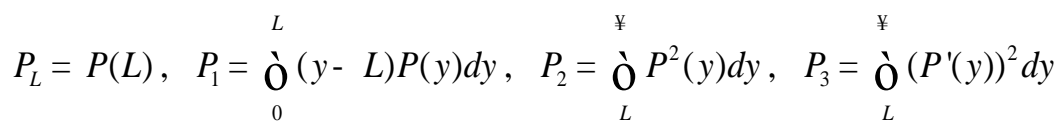
$\left(C_{1}, C_{2}\right)$, i.e., the solution of the system of equations: 


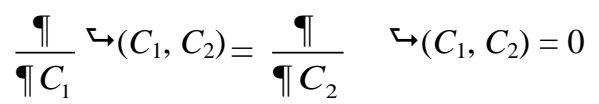

leads to the following result:

$$
\left\{\begin{array}{l}
C_{1}=\frac{-6 b(\psi-1) D P_{L}^{2} P_{1}}{2 P_{L}^{2}\left(1-\psi^{2}\right) L^{3}+(1-\psi) D^{2} P_{2}+2 D^{4} P_{3} / 15} \\
C_{2}=\frac{-C_{1}}{2 D}\left(\psi L^{2}-\frac{D^{2}}{3}\right)
\end{array}\right.
$$

290 With this expression, the potential after crack initiation (Eq.(35)) is calculated as follows:

$$
\begin{gathered}
f \hookrightarrow(\underline{u}) \\
=(\lambda+2 \mu)\left[-\frac{1}{2} b^{2} D \int_{0}^{\infty} P^{2} d y+C_{1} b(\psi-1) P_{1}+\frac{\left(1-\psi^{2}\right) C_{1}^{2} L^{3}}{6 D}+\frac{(1-\psi) D C_{1}^{2}}{12 \mathrm{P}_{L}^{2}} P_{2}+\frac{C_{1}^{2} D^{3}}{90 \mathrm{P}_{L}^{2}} P_{3}\right]
\end{gathered}
$$

291 From Eqs. (24), (28) and (38), it can be obtained that:

$$
\frac{E}{\lambda+2 \mu}=-C_{1} b(\psi-1) P_{1}-C_{1}^{2}\left[\frac{\left(1-\psi^{2}\right) L^{3}}{6 D}+\frac{(1-\psi) D}{12 P_{L}^{2}} P_{2}+\frac{D^{3}}{90 P_{L}^{2}} P_{3}\right]
$$

292 By replacing the $C_{1}$ presented in Eq. (37), the normalized dissipated energy by cracking in the approximate energy approach becomes:

$$
\frac{\mathrm{E}}{L}=\frac{(\lambda+2 \mu) 45 D P_{L}^{2} b^{2}(\psi-1)^{2} P_{1}^{2}}{L\left[30 \mathrm{P}_{L}^{2}\left(1-\psi^{2}\right) L^{3}+2 D^{4} P_{3}+15(1-\psi) D^{2} P_{2}\right]}
$$

It can be seen that this normalized dissipated energy by cracking in this approach is a function of the cracks depth $L$, the half spacing $D$, the soil properties though the term $\psi$ and the given suction field $P(y)$.

\section{Numerical approach}

In this work, approximate analytical solutions are compared with the results obtained by the numerical method. Simulations are performed with the Finite Element code Porofis [48] which is a research code derived from the commercial code DISROC built for coupled hydro-mechanical processes in porous fissured materials. The equations used in this paper, for governing hydraulic flow and mechanical 
deformation in cracked and unsaturated porous materials, have been presented in detail in previous papers [49-51]. They are here briefly summarized.

303

304

\subsection{Hydraulic behavior}

The moisture transfer process in a homogeneous porous and unsaturated material representing the soil is simulated. The flow in the soil around the cracks is governed by Darcy's law, while the flow in the cracks is governed by the cubic law [52], and they satisfy the mass conservation condition. During desiccation, the suction evolution is related to the degree of saturation by the Van Genuchten model [53] expressed by the following equation:

$$
\frac{S-S_{r e s}}{1-S_{r e s}}=\frac{1}{\left(1+(\theta p)^{n}\right)^{m}}
$$

where $S_{\text {res }}$ is residual degree of saturation and $\theta, n, m$ are constants.

The equation that allows determining the flow in the soil matrix with an assumption of incompressible fluid can be written as follows [54]:

$$
\operatorname{div}\left(\frac{\boldsymbol{k}}{\rho g} \nabla p\right)=C_{M} \frac{\partial p}{\partial t}
$$

where $C_{M}=S\left(\frac{1}{N}+\frac{\phi S^{\prime}}{S}\right), \boldsymbol{k}$ is the soil hydraulic conductivity, $g$ is the gravitational acceleration, $N$ is the Biot modulus, $\phi$ represents the porosity, and $S^{\prime}$ is the derivative $d S / d p$ calculated from the water retention curve.

For the cracks, the transversal conductivity between the two crack walls is infinitely high. This implies that the pressure is continuous between the two opposite faces of the crack and that the pressure takes the same value $p$ for a given point along the crack. The equation, which allows calculating the pressure for every location $\underline{S}$ along the crack, can be written as below:

$$
\nabla_{s} \cdot\left(c \partial_{s} p\right)=r^{m f}+r^{f}
$$


where $r^{m f}=\|\underline{v}\| \cdot \underline{n} ; r^{f}=\frac{\partial e}{\partial t}$,

320 In this equation, $\nabla_{s}()$ designates the divergence in the crack. The fluid-crack mass exchanges are

321 taken into account by the jump of fluid velocity across the crack $\|\underline{v}\|$ by presenting the discontinuity

322 with velocity values $\underline{v}^{+}$and $\underline{v}^{-}$for two faces of the crack. $\underline{n}$ is the normal unit vector to the crack

323 surface. $c$ is the tangential conductivity of the crack (parallel with the two crack walls) that can be

324 evaluated with the crack opening $e$ by the cubic law.

\subsection{Mechanical behavior - Cohesive zone model for the crack}

For the mechanical problem, the crack initiation and propagation are modeled by placing joint elements with Cohesive Zone Model (CZM) behavior. The CZM has been proposed as an alternative to Linear Elastic Fracture Mechanics to model crack propagation and takes its origin from the works of Dugdale [55], Barenblatt [56]. It is based on two key parameters: tensile strength and work of separation (or fracture energy) [57,58]. Thus, the CZM incorporates both energy and strength criteria [59]. Numerous developments have been introduced since the original Dugdale-Barenblatt's model to consider compression, shear and mixed loadings [60-65]. The CZM has been widely used because it avoids stress singularity at the fracture tip and can be easily implemented in a numerical code $[66,67]$. The CZM has been used more recently to study fracture propagation or hydric cracking in soil and rock type materials [68] and for microstructural approach of porous fractured solids [69,70].

An advanced CZM model was proposed by Pouya and Bemani [63], which covers both normal and shear loads. This model was successfully applied to the analysis and modeling of a set of tensile and shear, monotonic and cyclic fracture experiments on different rocks. This model is available in the numerical code Porofis and was used for the present study.

The following equation is used to simulate the cohesive damage crack behavior:

$$
\underline{\sigma}=(1-d) \boldsymbol{R} \underline{u}
$$


where $\underline{\sigma}$ is the stress vector on the matrix/crack interface surface, $\underline{n}$ is the normal unit vector on this

342 surface, $\boldsymbol{R}$ is the joint stiffness tensor and $d$ a scalar damage variable.

343 The strength criterion $\mathrm{F}(\underline{\sigma}, d)$ for this model depends on three parameters $\sigma_{\mathrm{R}}, C$ and $\varphi$ (which represent

344 respectively the tensile strength, cohesion and friction angle of the interface) and a function $g(d)$ 345 controlling the strength degradation with damage variable $D$. It has the following expression (See 346 Figure 3a):

$$
F(\underline{\sigma}, d)=\tau^{2}-\sigma_{n}^{2} \tan ^{2} \varphi+2 g(d) \sigma_{c} \sigma_{n}-g^{2}(d) C^{2}
$$

347 In mode I propagation, the damage evolution law induces a relation between $d$ and opening $u_{n}$ for a 348 monotonic traction loading given by the following relation:

$$
\begin{cases}d=0 & \text { for } u_{n}<u_{0} \\ d=1-e^{-\frac{\left(u_{n}-u_{0}\right)}{\beta u_{0}}} & \text { for } u_{n} \geq u_{0}\end{cases}
$$

349 where $u_{n}$ is the normal component of the displacement discontinuity $\underline{u}$ through the two crack walls,

$u_{0}=\frac{\sigma_{R}}{R_{n n}}$ is the elastic displacement limit, with $R_{n n}$ the normal component of the joint stiffness, and $\beta$ a parameter related to the ductility of the damage process (see Figure 3b). The function $g$ has the following expression:

$$
g(D)=(1-d)(1-\beta \ln (1-d))
$$

353 For the intact state, $d=0, g=1$ and a hyperbolic shape criterion can be obtained, which is similar to 354 those proposed by Ekelen [71] for soils and Carol al. [62] for quasi-brittle materials. At the final 355 failure state, $d \rightarrow 1$ and $\mathrm{g} \rightarrow 0$ and purely frictional interface with zero cohesion can be found. 


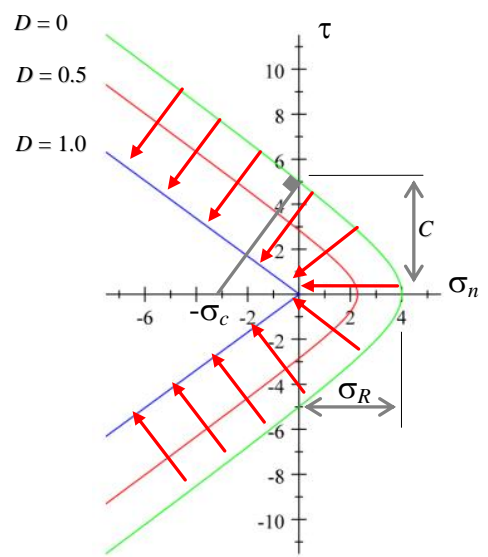

(a)

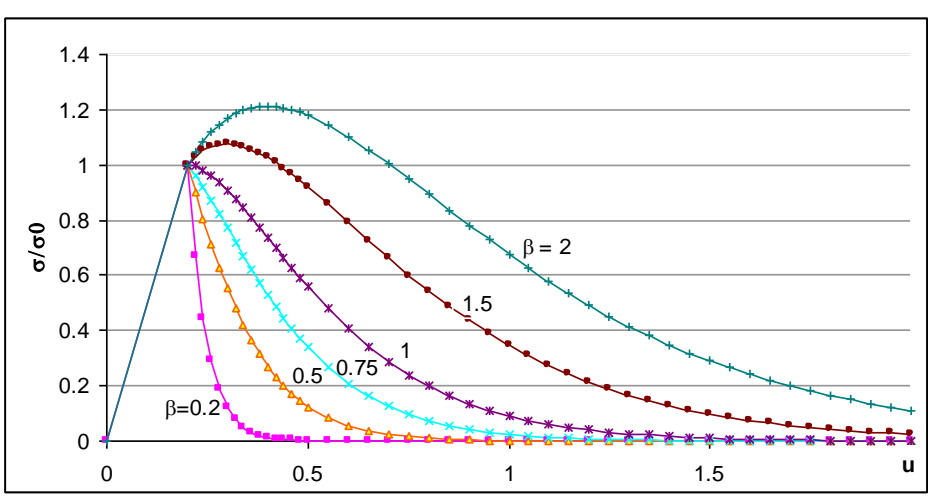

(b)

Figure 3. (a) Evolution of the criterion from the intact condition (green) to a frictional law (blue) during damage process (red arrows)), and (b) Traction-Separation law of the model for mode I propagation [63]

In the context of desiccation cracking, the crack propagation occurs mainly under the mode I and it is mainly controlled by the parameter $\sigma_{R}$ of the model related to the tensile strength of the material. The parameter $C$ has no significant effect on the propagation process.

The fracture energy dissipation rate $G^{c}$ can be related to the stress intensity factor $K_{I C}$, the elasticity modulus and the Poisson ratio in the framework of the LEFM [72]. Moreover, the equivalence of the LEFM and the CFM has been established in terms of crack propagation. The fracture energy dissipation rate $G^{c}$ is obtained by the integral of the surface under the traction-separation law and its expression as a function of cohesive crack parameters is proposed as follows [63]:

$$
G^{c}=[1 / 2+\beta(\beta+1)] \frac{\sigma_{R}^{2}}{R_{n n}}
$$

The effective stress is formulated to describe the mechanical behavior of the soil matrix and the failure criterion of the cohesive cracks. The suction is calculated in the matrix from the governing equations given in the previous section, whereas the crack is supposed to be empty and therefore no fluid 
pressure exists in the crack. The effective stress takes different values in the crack (joint elements) and in the matrix whereas the continuity of total stress is ensured at the interface between the matrix and the joint elements.

The crack opening $e$ changes with the deformation from the initial value $e_{0}$ to:

$$
e=e_{0}+u_{n}
$$

This crack opening change is considered to modify its hydraulic conductivity. The soil matrix is assumed to be an isotropic elastic linear material obeying Eq.(2).

\subsection{Hydro-mechanical coupling}

The coupling between mechanical and hydraulic problems is performed by a sequential resolution of the two problems and the interactions between them. For each time increment, the hydraulic problem is calculated in the beginning by Eqs. (42) and (43). The outputs corresponding to soil suction, degree of saturation and hydraulic conductivity of soil are then used as inputs for the mechanical problem. For the soil matrix, the hydro-mechanical coupling (Eq.(2)) allows updating the effective stress and calculating the soil strain. The effect of soil strain on the pore pressure field is ignored. The mechanical problem results are then input into the hydraulic problem to change the crack opening $e$ (Eq.(43)) and update the hydraulic conductivity of the crack $c$ following the cubic law [52].

\section{Comparison between analytical and numerical results}

\subsection{Model parameters and boundary conditions for numerical simulation}

The numerical simulation presented here focuses on a single crack propagation supposing that the crack spacing is known. A rectangular sample of $1 \mathrm{~m}$ in width, supposed to represent the crack spacing, and $4 \mathrm{~m}$ in height, supposed to be greater than the ultimate crack depth, is simulated (see Figure 4). Joint elements are inserted by the code Porofis [48] in the FEM model on the crack propagation path which is considered to be known in the present work. The initial stiffness of the 
crack, before damage, is high and so the presence of the joint elements in the model does not affect the 396 deformability of the model before cracking.

397 For the mechanical boundary conditions: the horizontal displacement is fixed on the two lateral sides;

398 the vertical displacement is prevented at the bottom of the sample; and the top surface is free to move 399 to simulate the settlement. For the hydraulic boundary condition, the desiccation is applied on the top 400 surface of the sample by a pore pressure that decreases with time. The variation of the applied pore 401 pressure with time can be expressed by the following function:

$$
p=p_{0}\left(1-e^{-\alpha t}\right)
$$

402 where $p_{0}$ is the final pore pressure on the top surface and $t$ is time. In this equation, $\alpha$ represents the 403 desiccation rate: a higher $\alpha$ corresponds to a faster desiccation. The geometry and the boundary 404 condition of the simulation are presented in Figure 4. The mesh is refined around the cohesive crack 405 line, almost on the first half from the surface in order to better capture the crack propagation. 


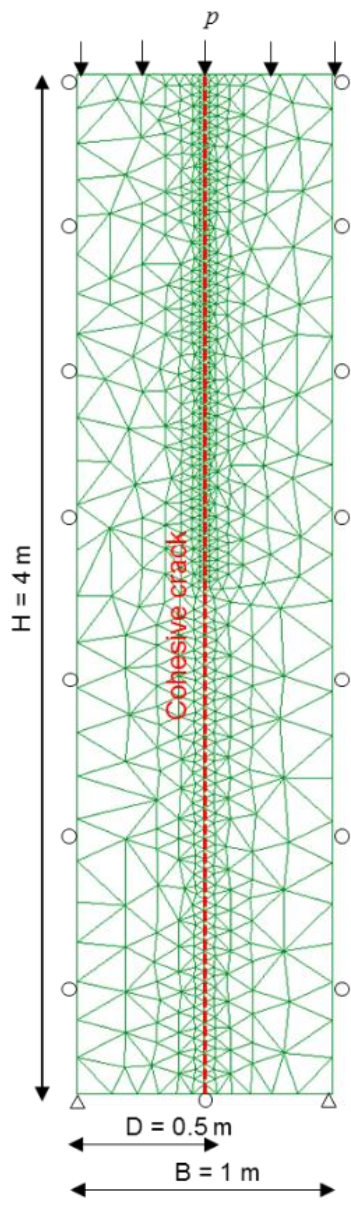

As explained above, the cohesive crack was used to model the desiccation cracks initiation and propagation. Several studies indicated that the desiccation cracking occurs mainly in opening mode (mode I) $[15,16,19,73]$ and this mode is also assumed in the present work. Thus, the main parameters of the cohesive crack are: normal joint stiffness $R_{n n}$, tensile strength $\sigma_{R}$, and initial crack opening $e_{0}$.

412 The crack tensile strength $\sigma_{R}$ was taken to be equal to the soil tensile strength. The initial value of the normal stiffness $R_{n n}$ is taken to be sufficiently high, and that of the hydraulic conductivity (related to the initial opening $e_{0}$ ) is sufficiently small so as to have negligible effects on the global elasticity and permeability of the model before cracking. The parameter $\beta$ in the damage model corresponds to the ductility of the material and can be obtained from the experimental curves [74]. In this work, $\beta$ was taken to be equal to 1 , which implies that the tensile stress of the fracture starts to decrease at the onset of damage (see Figure 3). The parameters $C_{\text {coh }}$ and $\varphi$ do not affect the mode-I crack propagation considered in the present work. However, these parameters must satisfy the inequality 
$C_{\text {coh }}=1.5 \sigma_{R} \tan \varphi$.

The soil parameters are identical to those used by Konrad \& Ayad [19]. The water retention curve is fitted from the experimental curve [19] with two constants $\theta, n(m=1-1 / n)$ of the Van Genuchten and the model.

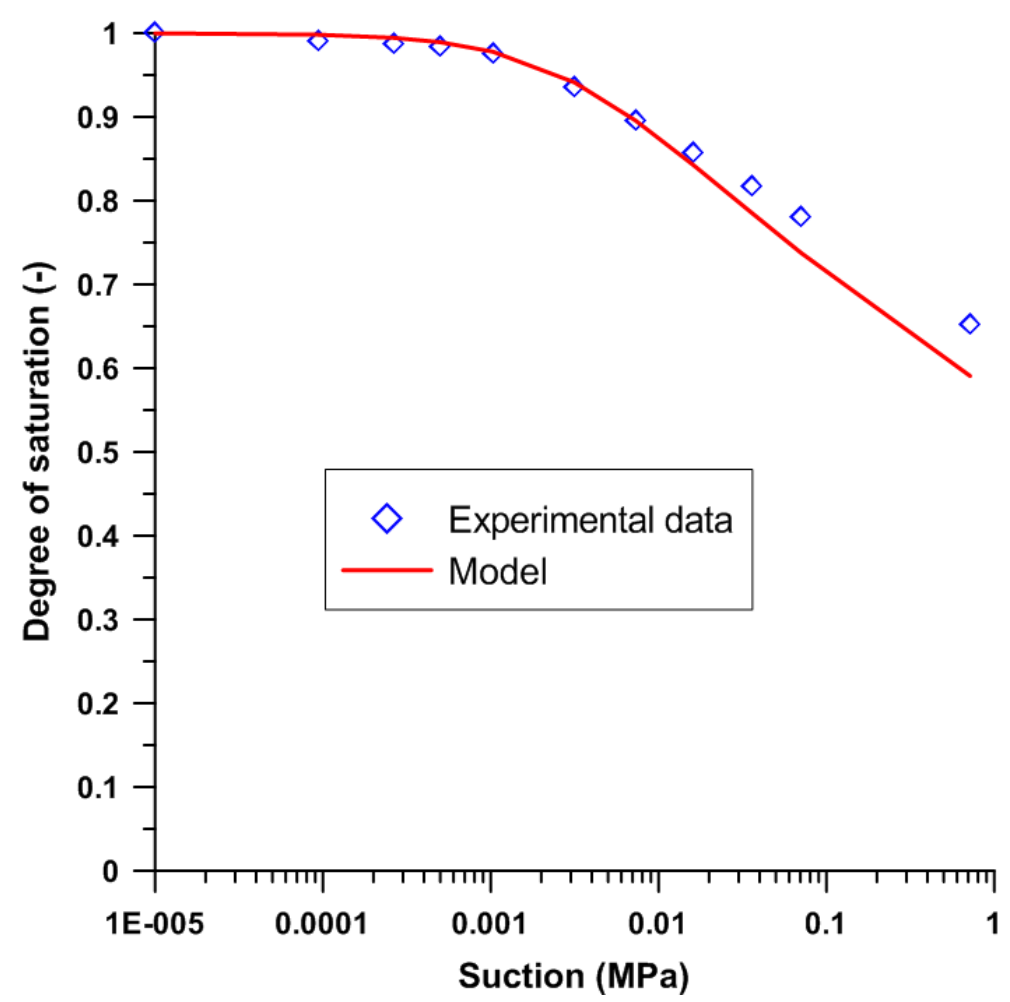

Figure 5 : Water retention curve (Experimental data from [19])

Table 1 presents the main parameters for the soil studied [19], for the cohesive crack and for the desiccation loading function used in numerical simulation. In this table, $E$ represents the soil elasticity modulus, $v$ is the Poisson ratio and $k_{s}$ is the hydraulic conductivity of soil at saturated state.

Table 1: Parameters of the numerical simulation

\begin{tabular}{|c|c|c|c|c|c|c|c|}
\hline \multirow{2}{*}{ Soil } & \multirow{2}{*}{$E(\mathrm{MPa})$} & \multirow{2}{*}{$v(-)$} & \multirow{2}{*}{$k_{s}(\mathrm{~m} / \mathrm{s})$} & \multicolumn{4}{|c|}{ Water retention curve (Van Genuchten model) } \\
\cline { 5 - 7 } & & & & $\theta\left(\mathrm{MPa}^{-1}\right)$ & $n(-)$ & $m(-)$ & $S_{\text {res }}(-)$ \\
\hline
\end{tabular}




\begin{tabular}{|l|l|l|l|l|l|l|l|}
\hline & 10 & 0.3 & $5 \times 10-6$ & 310 & 1.1 & 0.09 & 0.02 \\
\hline
\end{tabular}

\begin{tabular}{|c|c|c|c|c|c|c|c|c|}
\hline Crack & $\begin{array}{c}R_{t t} \\
(\mathrm{MPa} / \mathrm{m})\end{array}$ & $\begin{array}{c}R_{n n} \\
(\mathrm{MPa} / \mathrm{m})\end{array}$ & $\begin{array}{c}R_{t n}=R_{n t} \\
(\mathrm{MPa} / \mathrm{m})\end{array}$ & $\begin{array}{c}\sigma_{R} \\
(\mathrm{MPa})\end{array}$ & $\begin{array}{c}C_{\mathrm{coh}} \\
(\mathrm{MPa})\end{array}$ & $\left(^{\circ}\right)$ & $e_{0}$ & $(-)$ \\
& 1 & 10000 & 0 & 0.01 & 0.006 & 20 & 1 & $10^{-5}$ \\
\hline
\end{tabular}

434

\begin{tabular}{|c|c|c|}
\hline Desiccation rate & $p_{0}(\mathrm{MPa})$ & $\alpha(-)$ \\
\cline { 2 - 3 } & -0.03 & 50 \\
\hline
\end{tabular}

435

4.2. Suction evolution and two phases of the desiccation process following the numerical 436 approach

$$
\mathrm{s}=\mathbf{\mathrm { MPa }} \quad \mathrm{s}=\mathbf{0 . 0 1 \mathrm { MPa }} \mathrm{s}=\mathbf{0 . 0 1 8 4 \mathrm { MPa }}
$$
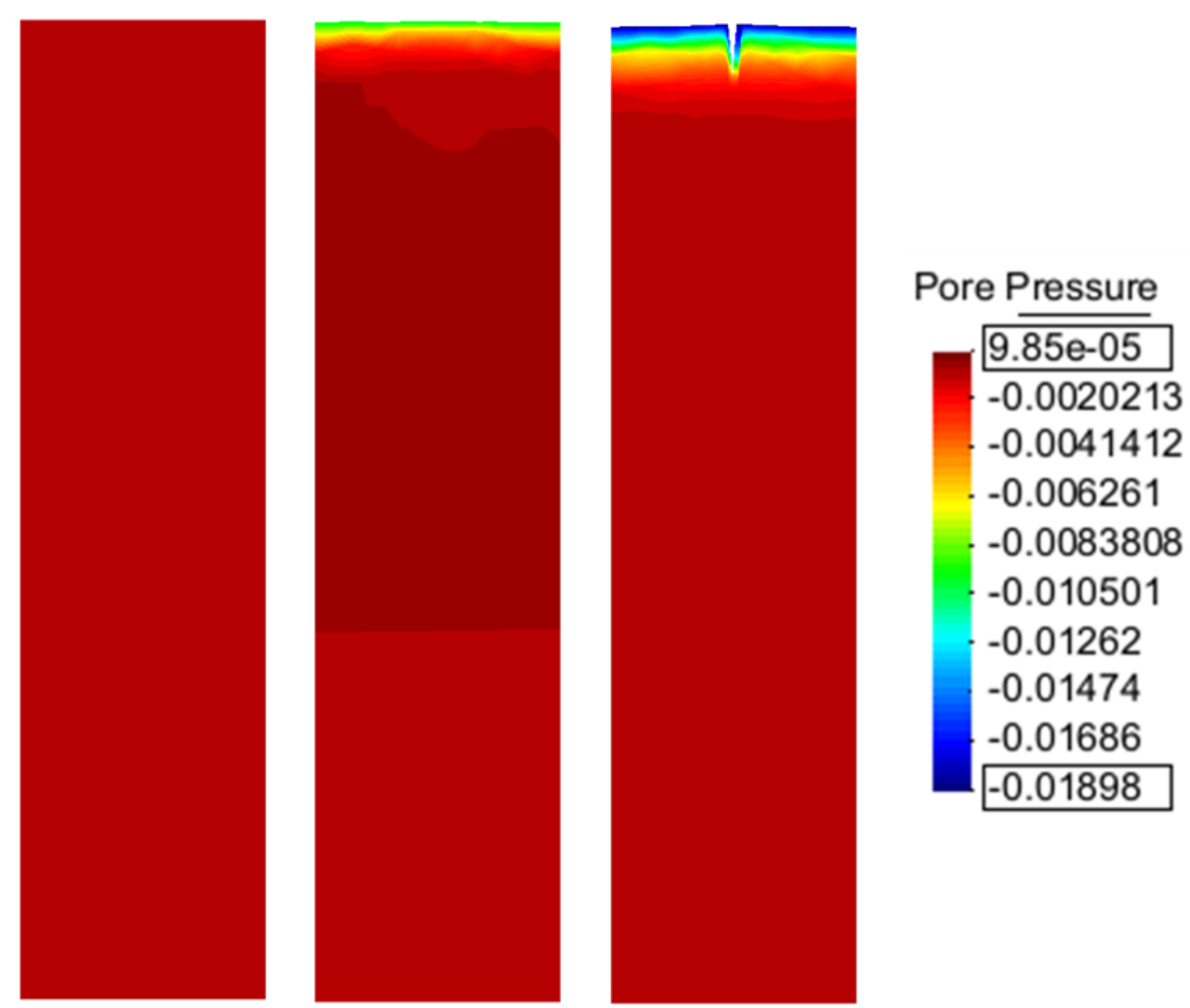


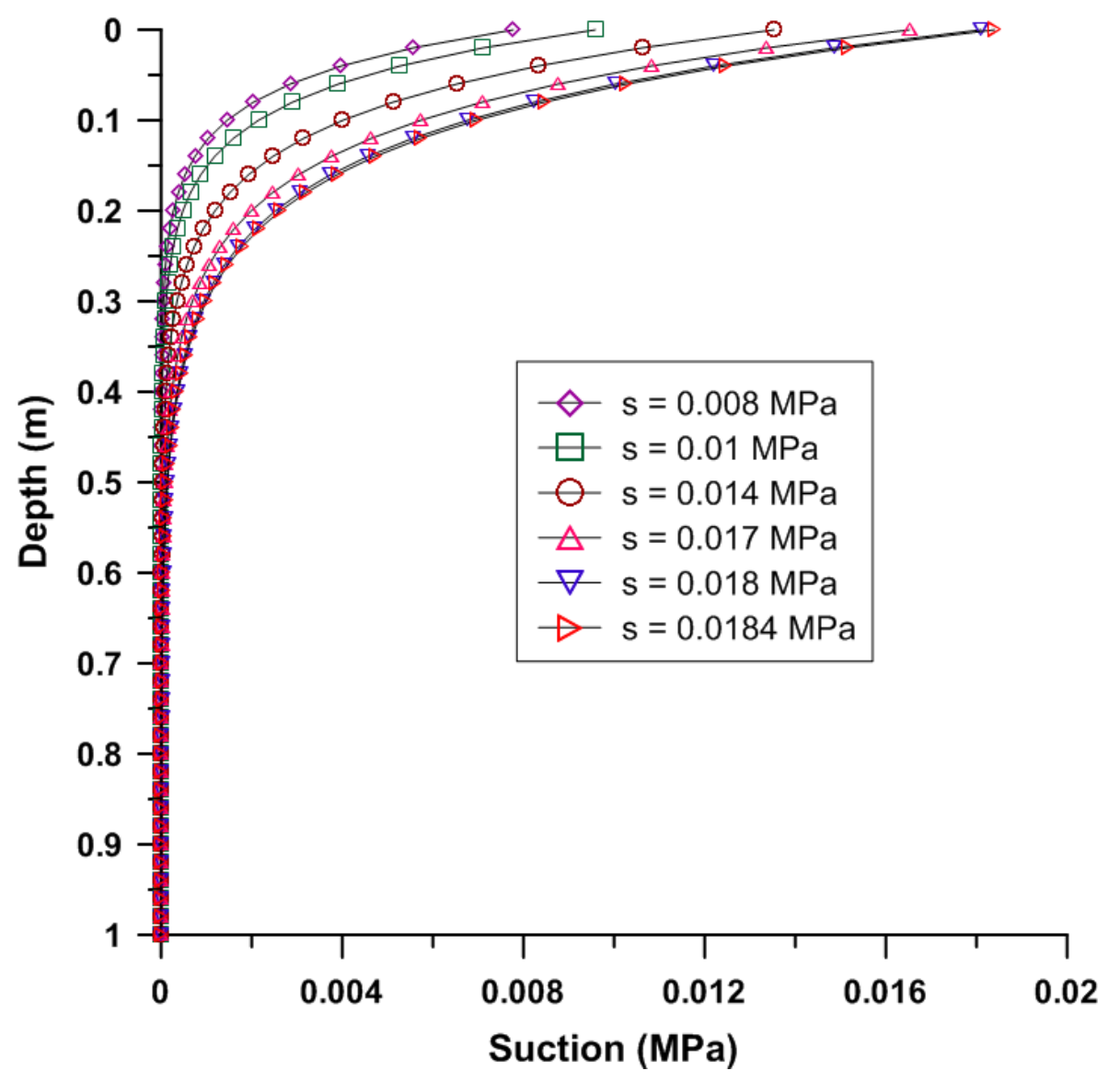

(b)

The Figure 6a shows the pore pressure distribution, including the deformed shape of the sample for three suctions at the top surface calculated by the numerical approach. Before cracking, the pore pressure is almost homogenous in each horizontal section. The suction profiles are presented in the Figure $6 \mathrm{~b}$ for various suctions at the top surface. It can be seen that the suction increases (or pore pressure decreases) gradually on the top surface due to the applied boundary condition. This suction penetrates from the top to the deeper parts of the sample due to moisture transfer. The highest suction is always on the top surface, and it decreases gradually with the depth. Two phases can be identified

451 from Figure 6a. In the first phase ( $s=0.01 \mathrm{MPa}$, for example), the sample presents only settlement without cracking, and the presence of the cohesive crack does not influence the pore pressure 
distribution. In the second phase ( $s=0.0184 \mathrm{MPa}$ ), the crack initiated partially by an opening, and the

crack hydraulic conductivity increases by representing higher suction values around its location (Figure 6a). The suction at the initiation of the crack was about $0.018 \mathrm{MPa}$. This suction is close to the air-entry value $(0.02-0.03 \mathrm{MPa})$ observed on the water retention curve plotted in the Figure 5 . This result is in agreement with previous experimental observations $[10,11,45]$.

The mechanism of crack initiation can be further studied in Figure 7 by the stress criterion. Figure 7 shows the tensile stress evolution of all joint elements along the line of the crack from the top surface to $1 \mathrm{~m}$ depth. It can be observed that, from $s=0.008 \mathrm{MPa}$ to $s=0.017 \mathrm{MPa}$, the tensile stress develops gradually in the upper part of the model (from $y=0$ to $y=0.5 \mathrm{~m}$ ), and the highest stress is on the top surface, which corresponds to the desiccation condition (Figure 6). In this period, the tensile stress increases but remains smaller than the tensile strength $(0.01 \mathrm{MPa})$. Therefore, all joint elements remain in the elastic phase in which no damage occurs and no crack can be observed. It is the first phase explained above where the sample presents only settlement without cracking (Figure 6a). When $s=0.018 \mathrm{MPa}$, the tensile stress at the top surface $(y=0)$ reaches the tensile strength $(0.01 \mathrm{MPa})$, the damage phase begins, and the second phase with the initiation of the crack starts. The propagation of the crack in the crack initiation phase occurs suddenly. When $s=0.0184 \mathrm{MPa}$, all joint elements from $y=0$ to $y=0.31 \mathrm{~m}$ are damaged. This damage is represented by the stress relaxation. This can be considered as the critical moment that distinguishes the two phases of the analysis: before and after crack initiation. 


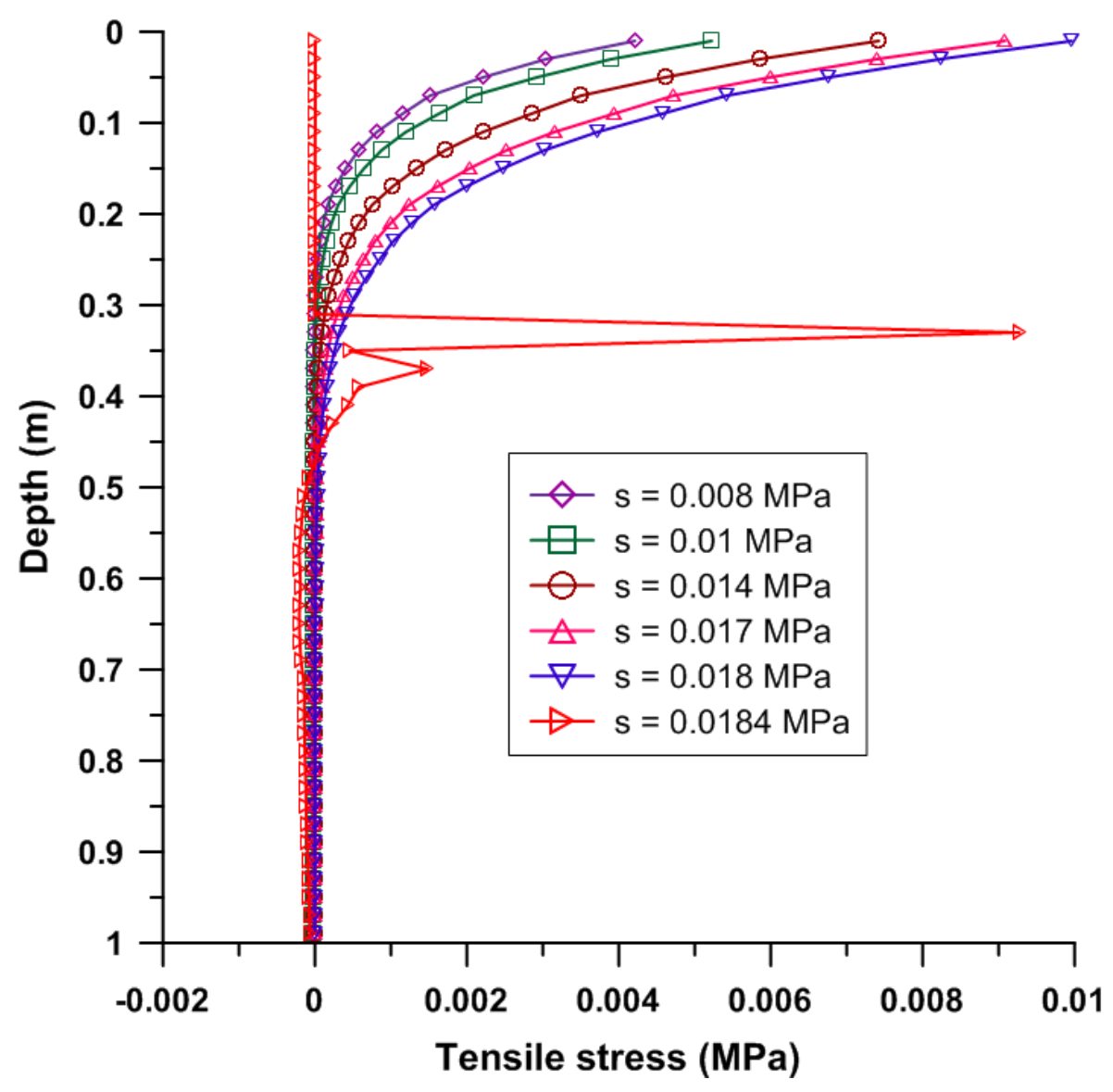

Figure 7: Tensile stress profile at various suctions on top surface following the numerical approach

\subsection{Displacements and energy before cracking}

As explained above, the horizontal displacement $u_{x}$ is assumed to be zero and the settlement $u_{y}$ varied only vertically before cracking. This settlement can be calculated analytically with the soil parameters and the suction profiles (Eq. (26)). From the given pore pressure distribution presented in Figure 6b, the settlement with the depth of the model is analytically calculated to compare with the numerical simulation results (see Figure 8). That shows good agreement between the settlements calculated by analytical solution (lines) and the ones calculated by numerical simulation (points). The settlement increases during the desiccation, and the maximum settlement is on the top of the sample. 


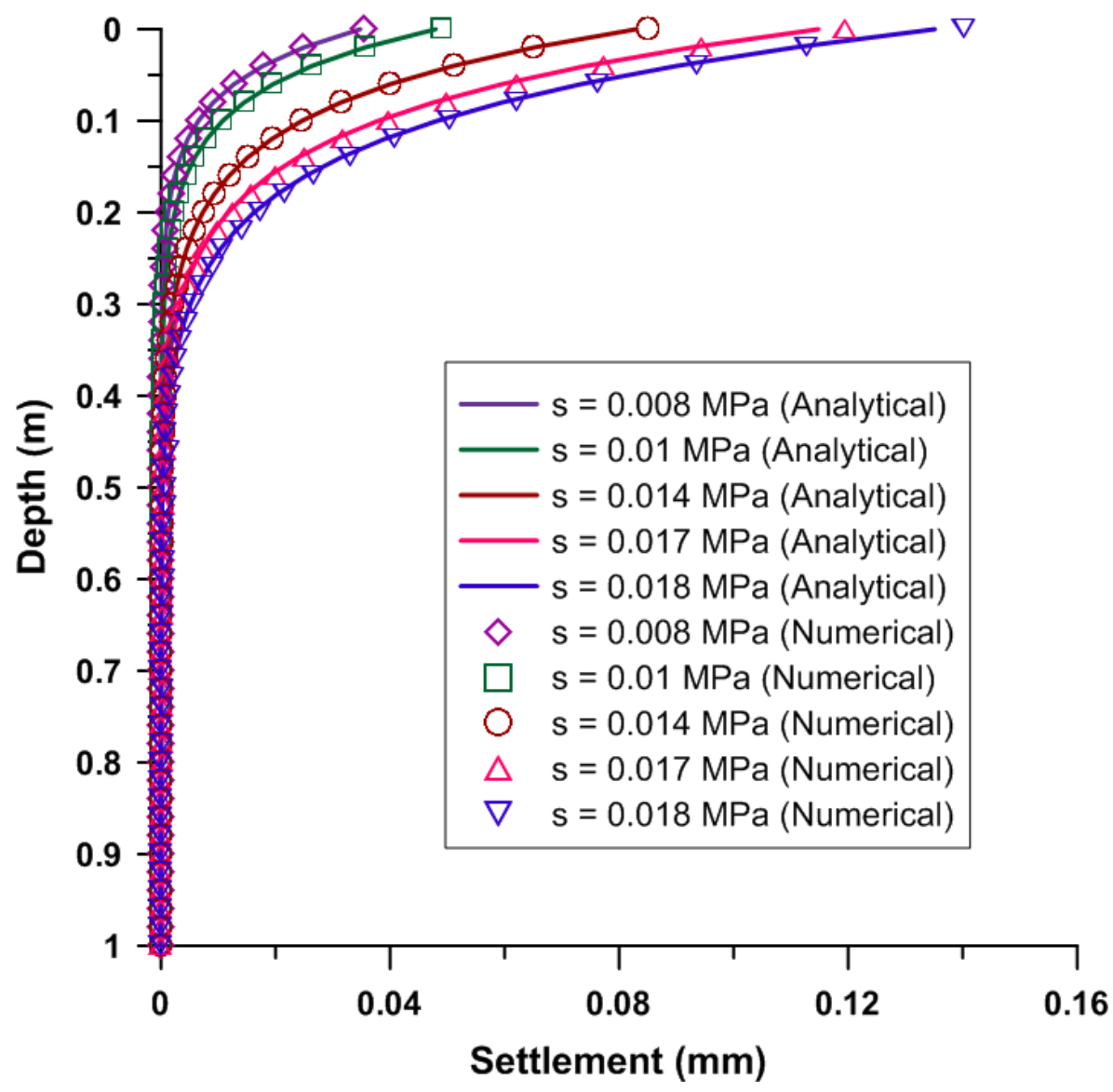




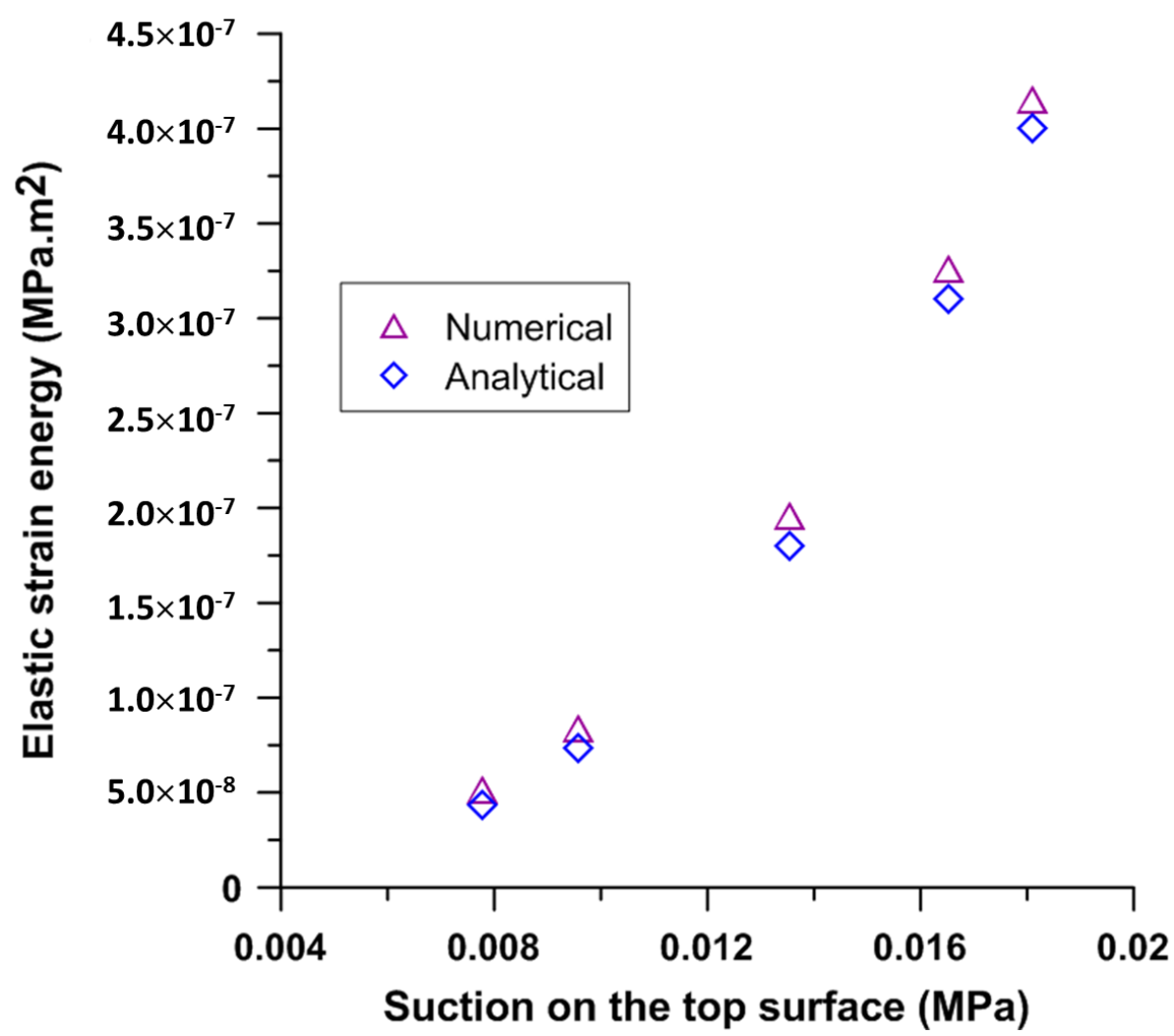

The elastic strain energy before cracking can be analytically calculated as a function of the soil parameters and the suction evolution (Eq. (27)). In the numerical simulation, the elastic strain energy $E^{\text {num }}$ of the sample is calculated by the following equation:

$$
E^{n u m}=\left[\frac{1}{2} \int_{\Omega}\left(\boldsymbol{\varepsilon}-\boldsymbol{\varepsilon}^{L}\right): \mathrm{C}:\left(\boldsymbol{\varepsilon}-\boldsymbol{\varepsilon}^{L}\right)+\frac{1}{2} \int_{\Omega} \underline{u}: \boldsymbol{R}: \underline{u}\right] d v
$$

493

where $\underline{u}$ and $\boldsymbol{R}$ are the opening and normal stiffness of the joint elements.

The Figure 9 shows good agreement between the elastic strain energy evolution for the numerical simulation and the analytical results.

\subsection{Crack depth in the initiation phase}

As mentioned above, in this simulation, the crack is initiated when $s=0.0184 \mathrm{MPa}$. The pore pressure profile at this moment can be applied in the analytical approach to calculate the energy released by cracking and to predict the crack depth in its initiation stage for a known half-spacing $D$. 
The energy evolution of the model during desiccation and the evolution of the crack depth in this

501 period are initially determined by the numerical simulation. In the numerical simulation, the crack depth is considered as the distance from the top surface to the last damaged joint element in which the damage variable is equal to 1 . During the desiccation, the tensile stress increases due to the increase of suction, and the damage process begins when the tensile stress reaches the tensile strength (Figure 7). The elastic strain energy of the sample is calculated by Eq.(48). Figure 10 shows the elastic strain energy and crack depth evolution calculated by the numerical simulation. At the beginning, from $s=0$ to $s=0.01835 \mathrm{MPa}$, the elastic strain energy of the sample increases due to the increase of suction (Figure 10a). During this period, the crack remains closed. At $s=0.01835 \mathrm{MPa}$, the elastic strain energy decreases markedly, and the energy is dissipated due to the initiation of a crack with a depth of $0.31 \mathrm{~m}$. It can be seen that this crack is propagated with two main phases: in the first phase, the crack propagates suddenly in a very short time (instable propagation phase) to reach an ultimate length (see Figure 10b), and in the second one, a stable and gradual propagation of the crack occurs.

513
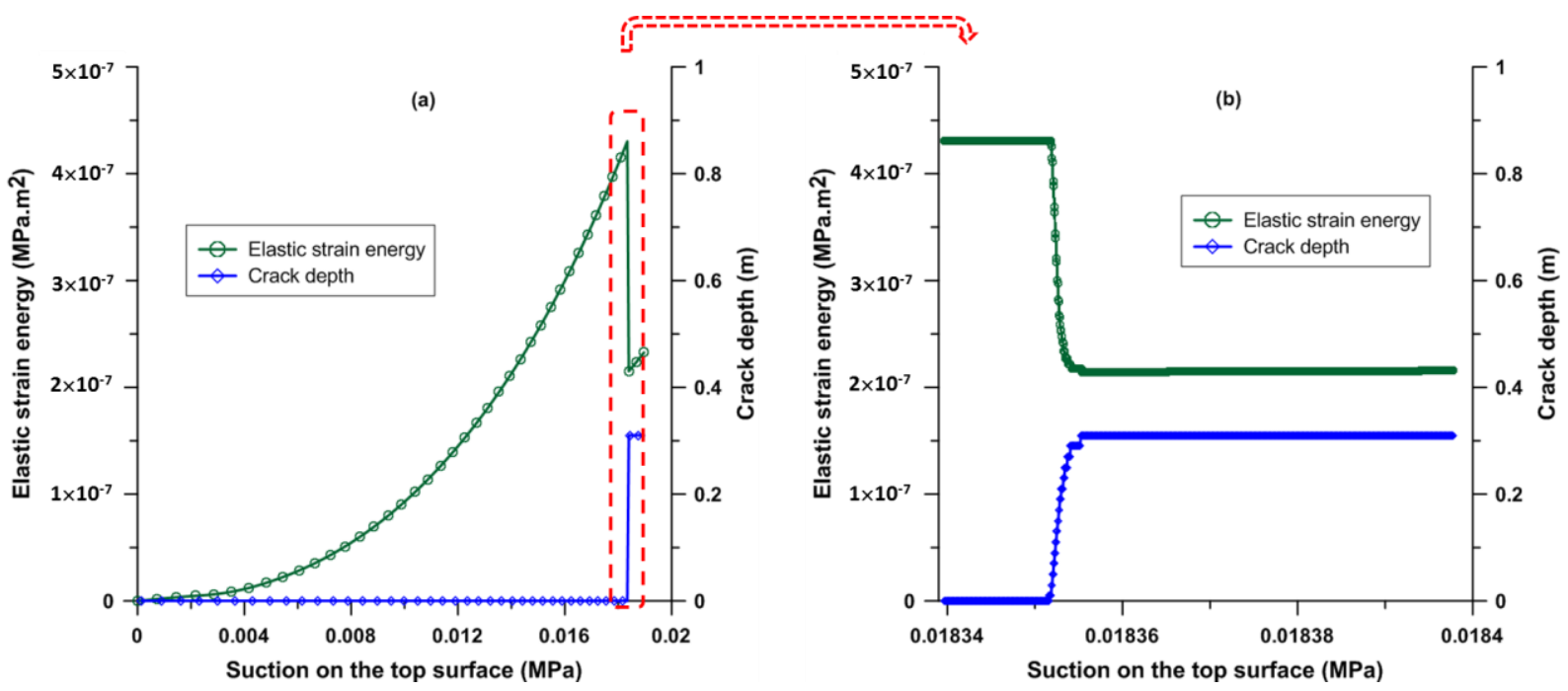

Figure 10: Elastic strain energy and crack depth versus suction on the top surface by the numerical approach

517 In the analytical approach, the pore pressure profiles numerically calculated (Figure 6b) are applied 518 (Eq.(40)) to calculate the normalized dissipated energy $\downarrow \uparrow / L$ for different crack depths. In the energy approach, the crack initiates when the energy criterion is satisfied, i.e., $\downarrow \uparrow / L \geq G^{c}$ (Eq.(25)). 
Figure 11 shows the normalized dissipated energy $\downarrow \uparrow / L$ (analytically calculated) versus crack depth for various suctions at the top surface. The fracture energy dissipation rate $G^{c}$ calculated by Eq.(48) is also plotted in this figure. It can be seen that the energy criterion is satisfied with $s=0.01 \mathrm{MPa}$ when the peak of the normalized dissipated energy curve $\downarrow \uparrow / L$ reaches $G^{c}$. If the energy criterion alone was sufficient for crack propagation, this state could be the onset of crack propagation. However, Figure 7 shows that, at this moment, the tensile stress is still smaller than the tensile strength. According to the Leguillon's theory the two criteria must be satisfied for the crack initiation takes place. This is well confirmed by the numerical simulation results since, even though the energy criterion is satisfied at this moment, this crack does not initiate. Then, the energy strain of the sample continues to accumulate with increasing suction. When, the tensile stress reaches the soil tensile strength $(s=$ $0.01835 \mathrm{MPa}$ ), Figure 7 , the criteria of both energy and stress are satisfied, and, at this moment precisely the crack starts to initiate and propagate (instantaneous energy drop and jump in the crack depth), Figure 10.

It is interesting to note that the energy criterion provides also an information on the crack depth. According to the energy criterion, the crack depth must satisfy the condition $\downarrow \uparrow / L \geq G^{c}$. Figure 11 shows that, at the crack initiation moment, $s \approx 0.01835 \mathrm{MPa}$, this condition is satisfied for $L=0.08$ to $1.65 \mathrm{~m}$. The crack depth $L$ corresponding to the peak value of $\downarrow \uparrow / L$ is approximately equal to $0.33 \mathrm{~m}$ for all the curves. This value of the crack depth is close to the one obtained by the numerical approach (see Figure 10). Note that Konrad \&Ayad [19] used LEFM to study the propagation of desiccation cracks in the same soil and found an ultimate crack depth of approximately $0.30 \mathrm{~m}$ with average spacing of 1-1.2 m (half-spacing is close to $0.5 \mathrm{~m}$, as in the case of the present study). These results were in agreement with in situ observation $[14,16]$. 


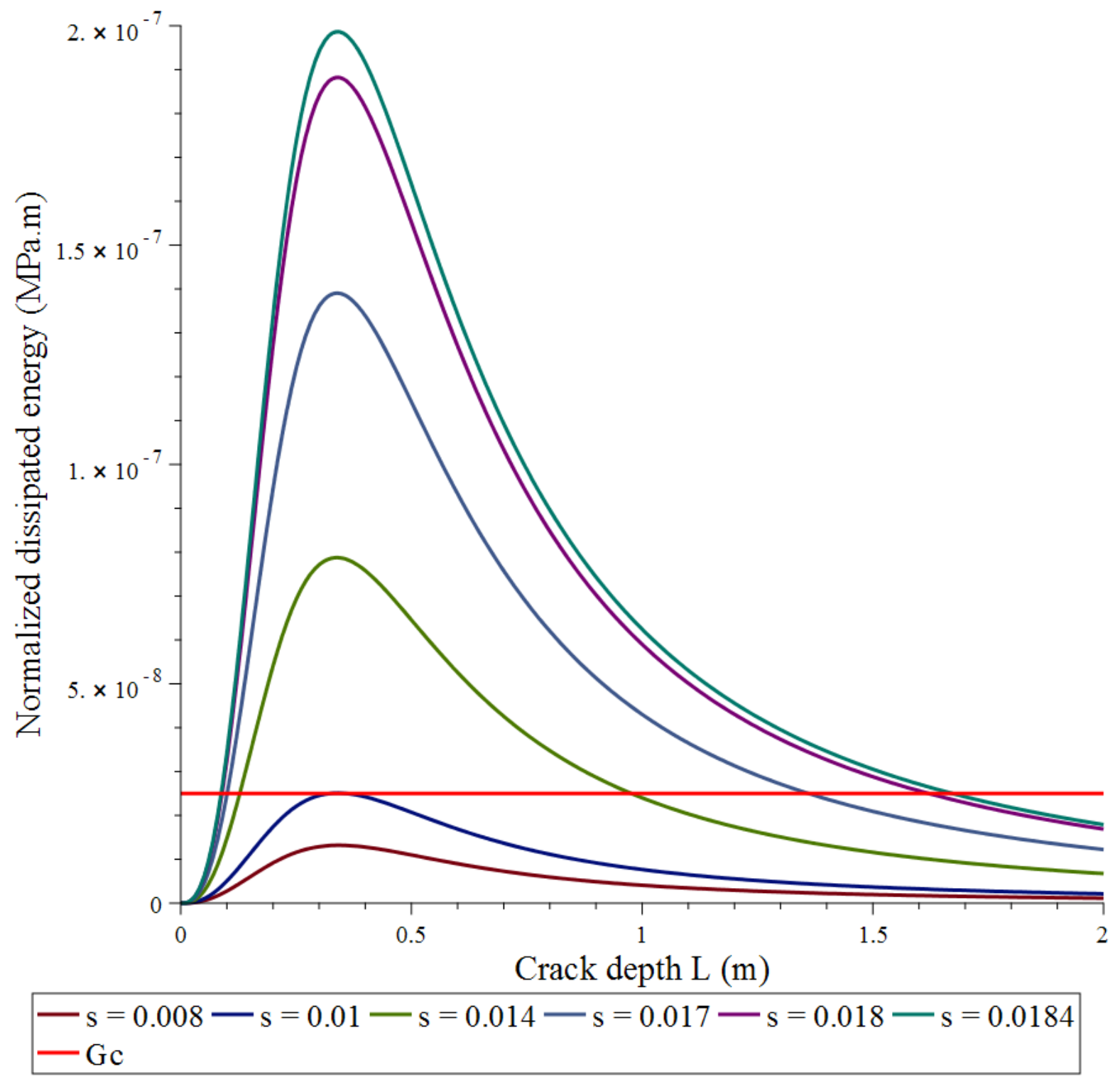

Figure 11: Normalized dissipated energy versus crack depth for various suctions on the top surface and the fracture energy dissipation rate $G^{c}$ by the analytical approach

\subsection{Displacements and energy after crack initiation}

547 In this section, the proposed approximate analytical solution of the displacement field after crack

548 initiation is compared with the numerical results. For this purpose, the suction distribution when $s=$

$5490.01834 \mathrm{MPa}$ and a crack depth of $L=0.31 \mathrm{~m}$ are considered in the analytical solution (Eqs. (32), (34)

550 and (37)) to calculate the displacement field. The left side of the crack (from $x=0-0.5 \mathrm{~m}$ ) is studied

551 in this part. As mentioned above, the subdomain $1 \Omega^{1}$ contains the crack with $y \leq L=0.31 \mathrm{~m}$, and the 
552 displacements can be calculated by Eq. (32). For the subdomain $2 \Omega^{2}$ below the crack with $y>L=$

$5530.31 \mathrm{~m}$, the displacements can be calculated by Eq. (34), and two constants $C_{1}$ and $C_{2}$ can be calculated

554 by Eq. (37).

555 Figure 12 shows the deformed mesh calculated by the numerical simulation (dashed lines) and the 556 analytical solution (continuous lines). The displacement presented here is amplified 300 times for a 557 clear visualization. The horizontal displacement in the crack line $(x=0.5 \mathrm{~m})$ shows the opening of the 558 crack. In this analytical solution, the horizontal displacement is approximated as a linear function of $y$.

559 It can be observed that the horizontal displacement is maximal on the crack line and decreases from 560 this line to the left side. In addition, the settlement after crack initiation is not uniform in each 561 horizontal section, but the maximal settlement is obtained on the left side (center of the unit cell 562 because of the symmetry conditions), and the minimal settlement is obtained on the crack line. A 563 reasonable agreement between the numerical simulation results and the approximate analytical 564 solution can be observed. 


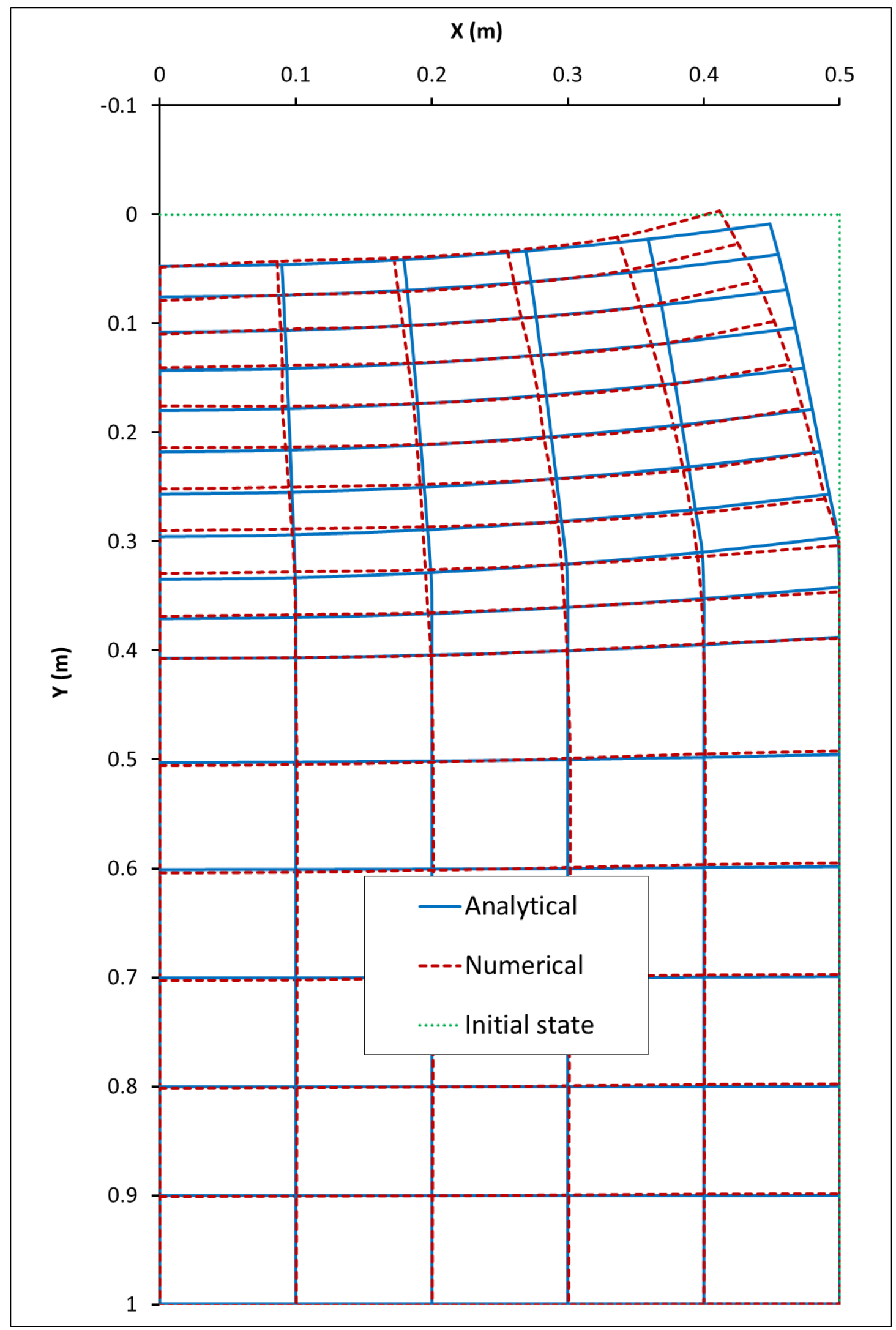


568 To investigate the effect of the half-spacing $D$ on the numerical results, the following values are considered: $0.4 \mathrm{~m}, 0.5 \mathrm{~m}, 0.6 \mathrm{~m}, 0.75 \mathrm{~m}$ and $1.0 \mathrm{~m}$ by using different meshes. In these tests, the same soil parameters and the same boundary conditions of the previous test are used. The numerical results show that the crack initiation occurs with a similar suction profile for all five tests $(s=0.016-0.019$ MPa). This suction profile is applied to calculate the normalized dissipated energy $\downarrow \uparrow / L$ using Eq. 39 . Figure 13 presents the evolution of the crack depth numerically calculated for the five tests with different half-spacing $D$ values. At the beginning, the crack is not initiated yet, which corresponds to the elastic phase of joint elements. When the damage criterion is reached, the crack propagates markedly to reach the ultimate depth. After this moment, the crack propagates slowly. From this figure, the ultimate crack depth in the crack initiation phase for each test can be determined by the numerical simulation.

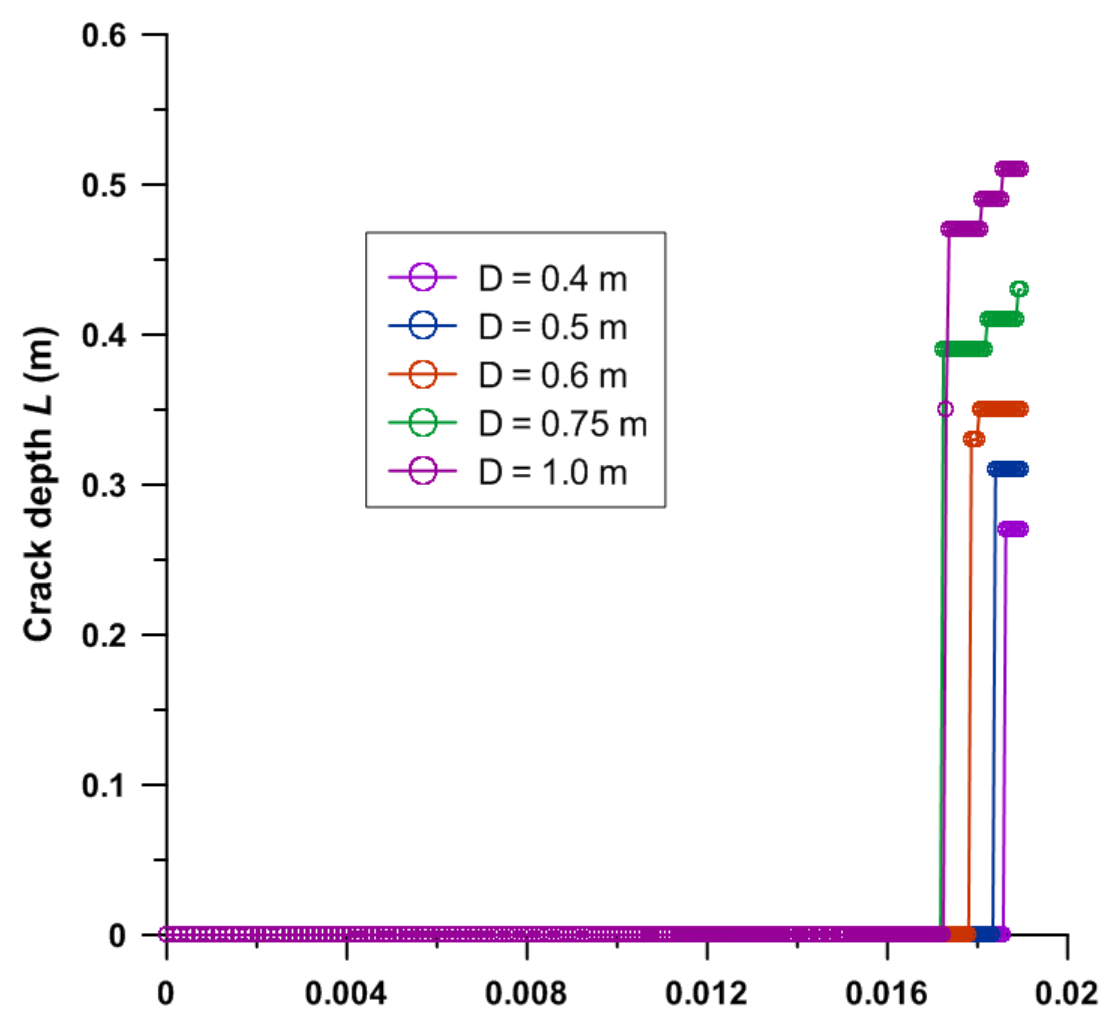

Figure 13: Crack depth versus suction on the top surface for various half-spacing values calculated by 
Figure 14 shows the normalized dissipated energy $\downarrow \uparrow / L$ versus the crack depth $L$ for various $D$ values calculated by the analytical approach (Eq.(40). These results allow determining the crack depth obtained by the energy approach if the crack depth corresponding to the peak of the $\downarrow \uparrow / L$ curve is accepted. Figure 15 presents the crack depth for different half-spacing values calculated by the numerical simulation and the analytical (energy) approach. A good agreement between the two approaches confirms that the crack depth analytically calculated is equal to the depth corresponding to the maximal normalized dissipated energy. From this conclusion, the proposed energy approach can be used to predict the crack depth in its initiation phase with a given spacing.

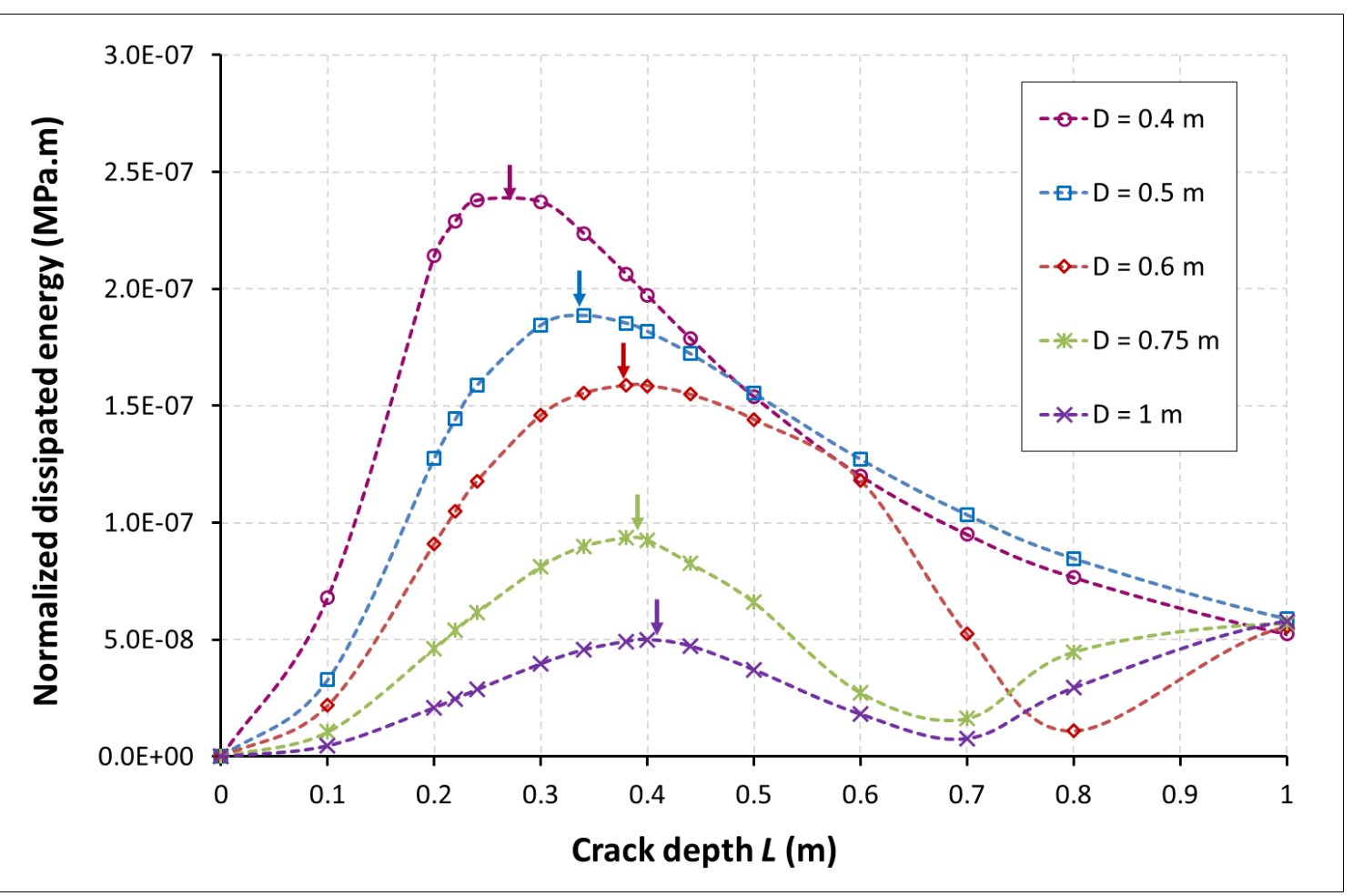

Figure 14: Normalized dissipated energy versus crack depth at crack initiation for different values of the half-spacing $D$ by the analytical approach 


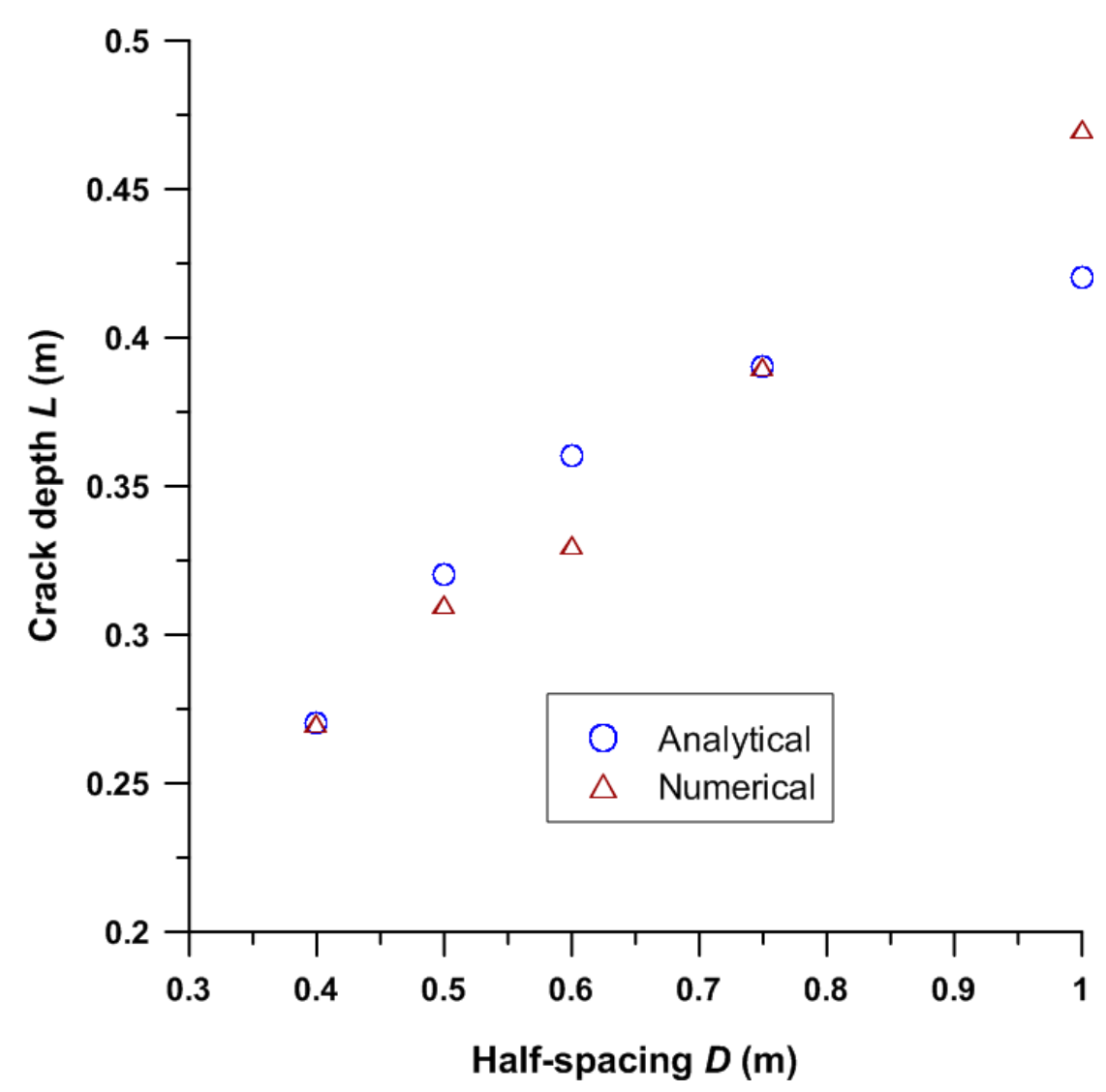

Figure 15: Crack depth versus half-spacing calculated by the numerical and analytical approaches

\section{Discussions}

The analytical study in this work is based on the approximation of the displacement field after crack initiation by simple functions of $x$ and $y$. A second-degree polynomial function of $x$ with coefficients depending on $y$ is considered. The dependency on $y$ is also restricted to a second-degree polynomial function along the crack depth. This approximation could be improved to obtain more accurate results. However, this simple solution seems to give reasonable values of displacement (Figure 12) and a good prediction of crack depth compared to the numerical results (Figure 15). depends on both crack depth and spacing. They allow predicting a crack depth corresponding to a given crack spacing and vice versa. The crack spacing can be considered as the distance between two neighboring opened cracks. Numerically, this spacing can be obtained by placing a set of cohesive cracks in the model. Some cracks will be opened and the spacing will be detected automatically. But 
the simulation of the multi-crack case is very challenging. In order to simplify the numerical simulation for a given crack spacing, a case of a single crack is investigated in this work. The cracking

611 process is then limited to the initiation and propagation of a single cohesive crack located in the 612 middle of the sample. Besides, in the present work the crack depth calculated analytically from 613 fracture energy analysis is compared with that obtained by numerical simulation; this latter combines 614 both the stress and energy criteria. This result is also in good agreement with the analysis of Konrad \& 615 Ayad based on LEFM [19] and in situ observation [14,16]. As mentioned above, the soil parameters 616 and the water retention curve used in this study are identical to those used by Konrad \& Ayad [19]. 617 The numerical results show that the crack initiates at a suction on the surface of $18 \mathrm{kPa}$, which is close 618 to that observed by Konrad \& Ayad [14] on the field (20 kPa). In addition, the value for the crack 619 depth experimentally observed was $0.3 \mathrm{~m}$ and the theoretical value obtained in the present work is also similar ( $0.31 \mathrm{~m}$ for $1 \mathrm{~m}$ spacing introduced in the model).

The proposed energy approach was established by assuming that a set of cracks with the same depth and same spacing appears instantaneously. This simplifies the problem and allows studying only one half of a periodic cell containing a crack. In reality, the cracking pattern evolves to form sequentially different families of cracks $([8,75])$. First, primary cracks are developed dividing the soil surface into cells and then subsequent drying tends to subdivide these cells in the form of secondary and tertiary crack families. In addition, the crack patterns observed experimentally by Peron et al. [34] showed that the crack network formation can result from the combination of two processes, "sequential infilling" and "simultaneous growing," since the cracks tend to appear either successively or simultaneously. The sequential infilling occurs to create different families of cracks, but the simultaneous growing can occur within each family. The "sequential infilling" concept for desiccation cracking should be 631 invoked only when cells of an intact material with a reduced, well-defined size can be individualized 632 [34]. The initiation of crack is influenced by the two major factors : stress distribution and presence of flaws [28]. Therefore, the simultaneous propagation can occur in the long specimens with few flaws 
within a short amount of time, is also a common observation $[14,76]$.The present approach represents the "simultaneous growing" process which can occur and create the cracks in one family.

637 The existence of an unstable or instantaneous crack propagation, corresponding to the crack initiation 638 phase considered in the present work, has already been observed experimentally in [9] where the crack 639 reached the ultimate depth in a short time. This ultimate depth corresponding to the unstable 640 propagation was also calculated by theoretical investigations [15,19]. It is interesting to note that, by 641 using cohesive joints elements, this phenomenon is found automatically as a result of numerical simulation of the process. It is also interesting to note that the energy criterion is satisfied before the stress criterion, and thus, at the initiation moment, some energy excess is available to make the

644 fracture propagate up to the ultimate depth. This vision conforms to Leguillon's theory [35,77] for crack initiation conditioned by a double stress and energy criteria. However, there is a difference in the present study concerning the stress condition. In Leguillon's theory, the stress on the entire crack length has to be greater than or equal to the tensile strength of the material. In this study, based on cohesive zone models, the damage in the joint elements, representing the crack propagation process, is triggered when the stress in the first element on the top surface of the sample reaches the stress limit.

650 As a result, the stress condition would be satisfied when the stress reaches the limit just on the soil surface. The opening of the first element on the top surfaces modifies then the tensile stress profile inducing the crack propagation (Fig. 6). Besides, according to Amarasiri \& Kodikara [24], when the available strain energy is larger than the required fracture energy for a full crack to develop, the crack can propagate to the full depth uncontrollably. They also used the cohesive crack method with softening law to model the desiccation cracking and indicated that in some cases there is more energy than needed for fracture propagation. In these cases (where the crack opening at which the stress drops to zero is small), the extra energy is likely to be converted mostly to kinetic energy, and cracks will propagate instantaneously. However, the kinetic energy is not considered explicitly in the present work.

\section{Conclusions}


661 In the present work, a complementary energy approach is proposed to analyze soil desiccation 662 cracking, which is commonly investigated by a stress approach. It allows predicting the ultimate crack 663 depth for a given crack spacing in the initiation phase by calculating the elastic strain energies before 664 and after crack initiation.

665 The results show that the energy criterion is reached before the stress criterion. However, the crack 666 initiates when both criteria are satisfied. The energy dissipation depends on the crack spacing and 667 depth. When the stress condition is satisfied, the energy condition is already satisfied for a set of 668 possible pair values (depth, spacing). The numerical analysis shows that the crack depth and its related 669 spacing can be predicted by the maximum dissipated energy per unit crack depth. This assumption is 670 based on numerical simulation results and requires further investigation. However, the results obtained 671 by this assumption show good agreement for the crack depth and the displacement field after crack 672 initiation between the analytical and numerical results.

673 Despite some limitations, the approximate analytical solution established in this study allows 674 estimating of the crack depth for given soil parameters, as well as the crack opening and soil 675 settlement, which are in good agreement with the numerical results. In the future work, the multi-crack 676 numerical simulation would be considered to confirm the findings of the present work.

\section{Acknowledgements}

678 The authors would like to thank Prof. Farimah Masrouri and Dr. Jean-Bernard Karzmierczak for their

679 valuable comments. 
1. Kindle E. Some Factors Affecting the Development of Mud-Cracks. Journal of Geology 1917;25:135-144.

2. Lau JT. Thesis : Desiccation cracking of soils. University of Saskatchewan, 1987.

685

3. Abu-Hejleh AN, Znidarcic D. Desiccation Theory for Soft Cohesive Soils. Journal of Geotechnical Engineering 1995;121(6):493-502.

4. Towner GD. The Mechanics of Cracking of Drying. Journal of Agricultural Engineering Research 1987;36(2):115-124.

5. Baker R. Tensile strength, tension cracks, and stability of slopes. Soils and Foundations

6. Yesiller N, Miller CJ, Inci G, Yaldo K. Desiccation and cracking behavior of three compacted landfill liner soils. Engineering Geology 2000;57:105-121.

7. Omidi GH, Thomas JC, Brown KW. Effect of desiccation cracking on the hydraulic conductivity of a compacted clay liner. Water, Air and Soil Pollution 1996;89:91-103.

8. Nahlawi H, Kodikara JK. Laboratory experiments on desiccation cracking of thin soil layers. Geotechnical \& Geological Engineering 2006;24:1641-1664.

9. Sanchez M, Atique A, Kim S, Romero E, Zielinski M. Exploring desiccation cracks in soils using a 2D profile laser device. Acta Geotechnica 2013;8(6):583-596.

10. Tang CS, Shi B, Liu C, Suo WB, Gao L. Experimental characterization of shrinkage and desiccation cracking in thin clay layer. Applied Clay Science 2011;52:69-77.

11. Peron H, Hueckel T, Laloui L, Hu L. Fundamentals of desiccation cracking of fine- grained soils : experimental characterisation and mechanisms identification. Canadian Geotechnical Journal 2009;46:1177-1201.

12. Corte A, Higashi A. Experimental Research on Desiccation Cracks in Soil. Army Snow Ice and Permafrost Research Establishment, Illinois, USA: 1960.

13. Li JH, Zhang LM. Study of desiccation crack initiation and development at ground surface. Engineering Geology 2011;123(4):347-358.

14. Konrad JM, Ayad R. Desiccation of a sensitive clay: field experimental observations. Canadian Geotechnical Journal 1997;34(6):929-942.

15. Lachenbruch A. Depth and spacing of tension cracks. Journal of Geophysical Research 1961;66(12):4273-4292.

16. Morris PH, Graham J, Williams DJ. Cracking in drying soil. Canadian Geotechnical Journal 1992;29(2):263-277.

17. Karalis TK, Karalis KT. A model for regular desiccation cracks formation. Acta Mechanica 2012;223(7):1517-1536.

18. Ayad R, Konrad JM, Soulié M. Desiccation of a sensitive clay: application of the model CRACK. Canadian Geotechnical Journal 1997;34(6):943-951.

19. Konrad JM, Ayad R. An idealized framework for the analysis of cohesive soils undergoing desiccation. Canadian Geotechnical Journal 1997;34(4):477-488.

20. Kodikara JK, Choi X. A simplified analytical model for desiccation cracking of clay layers in laboratory tests. Fourth International Conference on Unsaturated Soils 2006, 2558- 2567.

21. Amarasiri AL, Kodikara JK, Costa S. Numerical modelling of desiccation cracking. International Journal for Numerical and Analytical Methods in Geomechanics 2010;35(1):8296.

22. Peron H, Delenne JY, Laloui, Youssoufi EI. Discrete element modelling of drying shrinkage 
and cracking of soils. Computers and Geotechics 2009;36:61-69.

23. Sánchez M, Manzoli OL, Guimarães LJN. Modeling 3-D desiccation soil crack networks using a mesh fragmentation technique. Computers and Geotechics 2014;62:27-39.

24. Amarasiri AL, Kodikara J. Numerical Modeling of Desiccation Cracking Using the Cohesive Crack Method. International Journal of Geomechanics 2013;13(3):213-221.

25. Deng G, Shen ZJ. Numerical simulation of crack formation process in clays during drying and wetting. Geomechanics and Geoengineering 2006;1(1):27-41.

26. Hirobe $\mathrm{S}$, Oguni K. Coupling analysis of pattern formation in desiccation cracks. Computer Methods in Applied Mechanics and Engineering 2016;607:470-488.

27. Sima J, Jiang M, Zhou C. Numerical simulation of desiccation cracking in a thin clay layer using 3D discrete element modeling. Computers and Geotechics 2014;56:168-180.

28. Kodikara J, Costa S. Desiccation Cracking in Clayey Soils: Mechanisms and Modelling. Multiphysical Testing of Soils and Shales 2013:21-32.

29. Rao BN, Rahman S. Mesh-free analysis of cracks in isotropic functionally graded materials. Engineering Fracture Mechanics 2003;70(1):1-27.

30. Rabczuk T, Belytschko T. Cracking particles: a simplified meshfree method for arbitrary evolving cracks. International Journal for Numerical Methods in Enginnering 2004;61(13):2316-2343.

31. Penev D, Kawamura M. Estimation of the spacing and the width of cracks caused by shrinkage in the cement-treated slab under restraint. Cement and Concrete Research 1993;23(4):925-932.

32. Chertkov VY, Ravina I. Modeling the crack network of swelling clay soils. Soil Science Society of America Journal 1998;62(5):1162-1171.

33. Chertkov VY. The Geometry of Soil Crack Networks. The Open Hydrology Journal 2008;2:34-48.

34. Peron H, Laloui L, Hu LB, Hueckel T. Formation of drying crack patterns in soils: A deterministic approach. Acta Geotechnica 2013;8(2):215-221.

36. Leguillon D. Strength or toughness ? A criterion for crack onset at a notch. European Journal of Mechanics-A/Solids 2002;21(1):61-72.

36. Martin E, Leguillon D, Carrère N. A coupled strength and toughness criterion for the prediction of the open hole tensile strength of a composite plate. International Journal of Solids and Structures 2012;49(26):3915-3922.

37. Costa S, Kodikara J, Barbour SL, Fredlund DG. Theoretical analysis of desiccation crack spacing of a thin , long soil layer. Acta Geotechnica 2018;13(1):39-49.

38. Roscoe KH, Schofield AN, Wroth CP. On The Yielding of Soils. Géotechnique 1958;8(1):2253.

39. Bishop A. The principle of effective stress. 1959.

40. Borja RI. On the mechanical energy and effective stress in saturated and unsaturated porous continua. International Journal of Solids and Structures 2006;43(6):1764-1786.

41. Nuth M, Laloui L. Effective stress concept in unsaturated soils : Clarification and validation of a unified framework. International Journal for Numerical and Analytical Methods in Geomechanics 2008;32(7):771-801.

42. Houlsby G. The work input to an unsaturated granular material. Géotechinique 1997;47(1):193-196.

43. Borja RI. Cam-Clay plasticity . Part V: A mathematical framework for three-phase deformation and strain localization analyses of partially saturated porous media. Computer Methods in Applied Mechanics and Engineering 2004;193:5301-5338. 
44. Le Pense S, Arson C, Pouya A. A fully coupled damage-plasticity model for unsaturated geomaterials accounting for the ductile - brittle transition in drying clayey soils. International Journal of Solids and Structures 2016;91:102-114.

45. Shin H, Santamarina JC. Desiccation cracks in saturated fine-grained soils : particle-level phenomena and effective-stress analysis. Géotechnique 2011;61(11):961-972.

47. Pandolfi A, Ortiz M. An eigenerosion approach to brittle fracture. International Journal for Numerical Methods in Enginnering 2012;92(8):694-714.

47. Eslami MR. Finite Elements Methods in Mechanics. Solid Mechanics and Its Applications 2014;216: 209-222.

48. Pouya A. A Finite Element code for flow and deformation in porous fractured materials and structures. Http://www.mecharock.net.

49. Pouya A. A finite element method for modeling coupled flow and deformation in porous fractured media. International Journal for Numerical and Analytical Methods in Geomechanics 2015;39(16): 1836-1852.

50. Vo TD, Pouya A, Hemmati S, Tang AM. Numerical modelling of desiccation cracking of clayey soil using a cohesive fracture method. Computers and Geotechics 2017;85:15-27.

51. Vo TD, Pouya A, Hemmati S, Tang AM. Numerical modelling of desiccation cracking of clayey soil. $3^{\text {rd }}$ European Conference on Unsaturated 2016; 1-6.

52. Zimmerman RW, Bodvarsson GS. Hydraulic Conductivity of Rock Fractures. 1994.

53. Van Genuchten MT. A Closed-form Equation for Predicting the Hydraulic Conductivity of Unsaturated Soils. Soil Science Society of America Journal 1980;44(5):889-897.

54. Richards LA. Capillary Conduction of Liquids Through Porous Mediums. Physics 1931;1(5):318-333.

55. Dugdale DS. Yielding of steel sheets containing slits. Journal of the Mechanics and Physics of Solids 1960;8(2):100-104.

56. Barenblatt GI. The mathematical theory of equilibrium cracks in brittle fracture. Advances in Applied Mechanics 1962;7:55-129.

57. Hutchinson JW, Evans AG. Mechanics of materials: top-down approaches to fracture. Acta Materialia 2000;48(1):125-135.

58. Elices M, Guinea GV, Gomez J, Planas J. The cohesive zone model : advantages, limitations and challenges. Engineering Fracture Mechanics 2002;69(2):137-163.

59. Chen CR, Mai YW. Comparison of cohesive zone model and linear elastic fracture mechanics for a mode I crack near a compliant/stiff interface. Engineering Fracture Mechanics 2010;77(17):3408-3417.

60. Stankowski T, Runesson K, Sture S. Fracture and slip of interfaces in cementitious composites. II: Implementation. Journal of Engineering Mechanics 1993;119(2):315-327.

61. Yang HY, Wang ML. Constitutive theory of interface behaviour in quasi-brittle materials. Journal of Engineering Mechanics 1994;120(12):2588-2603.

62. Carol I, Prat PC, Lopez CM. Normal/Shear cracking model: Application to discrete crack analysis. Journal of Engineering Mechanics 1997;123(8):765-773.

63. Pouya A, Bemani P. A damage-plasticity model for cohesive fractures. International Journal of Rock Mechanics and Mining Sciences 2015;73:194-202.

64. Liu T, Cao P, Lin H. Damage and fracture evolution of hydraulic fracturing in compressionshear rock cracks. Theoretical and Applied Fracture Mechancis 2014;74:55-63.

66. Pandolfi A, Conti S, Ortiz M. A recursive-faulting model of distributed damage in confined brittle materials. Journal of the Mechanics and Physics of Solids 2006;54(9):1972-2003. 
66. Shet C, Chandra N. Analysis of energy balance when using cohesive zone models to simulate fracture processes. Journal of Engineering Materials and Technology 2002;124(4):440-450.

67. Gui YL, Hu W, Zhao ZY, Zhu X. Numerical modelling of a field soil desiccation test using a cohesive fracture model with Voronoi tessellations. Acta Geotechnica 2018;13(1):87-102.

68. Sarris E, Papanastasiou P. Modelling of hydraulic fracturing in a poroelastic cohesive formation. International Journal of Geomechanics 2011;12(2):160-167.

69. De Bellis ML, Della Vecchia G, Ortiz M, Pandolfi A. A linearized porous brittle damage material model with distributed frictional-cohesive faults. Engineering Geology 2016;215:1024.

70. De Bellis ML, Della Vecchia G, Ortiz M, Pandolfi A. A multiscale model of distributed frcature and permeability in solids in all-round compression. Journal of the Mechanics and Physics of Solids 2017;104:12-31.

71. Van Eekelen HAM. Isotropic yield surfaces in three dimensions for use in soil mechanics. International Journal for Numerical and Analytical Methods in Geomechanics 1980;4(1):89101.

72. Griffith A. The Phenomena of Rupture and Flow in Solids. Philosophical Transactions of the Royal Society of London 1921;221:163-198.

73. Amarasiri AL, Costa S, Kodikara JK. Determination of cohesive properties for mode I fracture from compacted clay beams. Canadian Geotechnical Journal 2011;48(8):1163-1173.

74. Backers T. Thesis: Fracture Toughness Determination and Micromechanics of Rock Under Mode I and Mode II Loading. University of Posdam, Germany, 2004.

75. Vo TD, Pouya A, Hemmati S, Tang AM. Modelling desiccation crack geometry evolution in clayey soils by analytical and numerical approaches. Canadian Geotechnical Journal 2018.

76. Miller CJ, Mi H, Yessiller N. Experimental analysis of desiccation crack propagation in clay liners. Journal of the American Water Ressources Association 1998;34(3):677-686.

77. Leguillon D, Lafarie-Frenot MC, Pannier Y, Martin E. Prediction of the surface cracking pattern of an oxidized polymer induced by residual and bending stresses. International Journal of Solids and Structures 2016;91:89-101. 


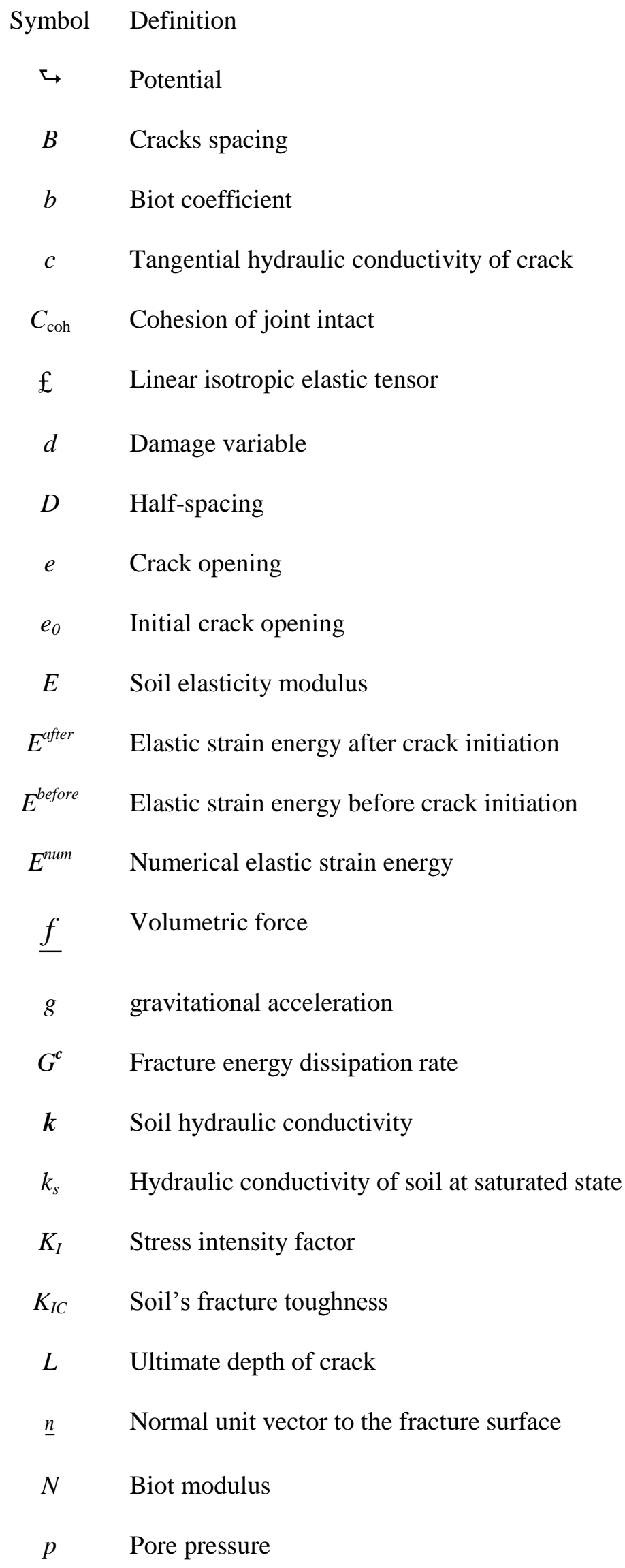




\begin{tabular}{|c|c|}
\hline$p_{0}$ & Final applied suction on the top surface \\
\hline$S$ & Degree of saturation \\
\hline$S_{\text {res }}$ & Residual degree of saturation \\
\hline$\underline{u}$ & Displacement vector \\
\hline$u_{n}$ & Normal component of displacement \\
\hline$u_{0}$ & Elastic displacement limit \\
\hline$t$ & Time \\
\hline$\underline{T}$ & Prescribed forces \\
\hline $\boldsymbol{R}$ & Joint stiffness tensor \\
\hline$R_{n n}$ & Normal component of joint stiffness \\
\hline$\|\underline{v}\|$ & Discontinuity velocity through two crack faces \\
\hline$\alpha$ & Constant representing desiccation rate \\
\hline$\beta$ & Parameter related to the material ductility \\
\hline$\gamma$ & Specific rupture energy per unit surface \\
\hline$\varphi$ & Friction angle \\
\hline$\delta$ & Kröneker or Unit tensor \\
\hline$\varepsilon$ & Strain tensor \\
\hline$\varepsilon^{0} ; \underline{u}^{0}$ & Strain and displacement solutions (before crack initiation) \\
\hline$\varepsilon^{s} ; \underline{u}^{s}$ & Strain and displacement solutions (after crack initiation) \\
\hline$\downarrow \uparrow$ & Dissipated energy by cracking \\
\hline$\lambda ; \mu$ & Lamé coefficients \\
\hline$v$ & Poisson ratio \\
\hline$\phi$ & Porosity \\
\hline$\theta, n, m$ & Constants of Van Genuchten model \\
\hline$\rho$ & Fluid density \\
\hline$\sigma$ & Total stress tensor \\
\hline
\end{tabular}


$\sigma^{\prime} \quad$ Effective stress tensor

$\sigma_{R} \quad$ Tensile strength

849 